\title{
DEVELOPMENT OF KINETIC MODELS FOR THE LIQUID PHASE METHANOL (LPMEOH $\left.^{\mathrm{TM}}\right)$ PROCESS
}

\author{
Topical Report
}

Prepared by

Xiang-Dong Peng

Contractor:

AIR PRODUCTS AND CHEMICALS, INC.

Allentown, PA 18195

June 2002

Prepared for the United States Department of Energy

Under Contract No. DE-FC22-94 PC93052 


\begin{abstract}
This report covers our recent work on the kinetics of the LPMEOH ${ }^{\mathrm{TM}}$ process. The major part of the report concerns the development of more robust kinetic models for the LPMEOH ${ }^{\mathrm{TM}}$ reaction system. The development was needed to meet the requirements for more accurate process simulations over a wide range of conditions. To this end, kinetic experiments were designed based on commercial needs and a D-Optimal design package. A database covering 53 different conditions was built. Two new reactions were identified and added to the LPMEOH ${ }^{\mathrm{TM}}$ reaction network. New rate models were developed for all 15 reactions in the system. The new rate models are more robust than the original ones, showing better fit to the experimental results over a wide range of conditions. Related to this model development are some new understandings about the sensitivity of rate models and their effects on catalyst life study.

The last section of this report covers a separate topic: water injection to the LPMEOH ${ }^{\mathrm{TM}}$ reactor and its effects on the LPMEOH ${ }^{\mathrm{TM}}$ process. An investigation was made of whether water injection can enhance the reactor productivity and how this enhancement depends on the composition of the major syngas feed. A water injection condition that resulted in $32 \%$ enhancement in productivity was observed. A catalyst life test under this water injection condition was conducted and showed no negative effects of water injection on catalyst stability.
\end{abstract}




\section{TABLE OF CONTENTS}

1. INTRODUCTION 1

2. EXPERIMENTAL 2

2.1. Apparatus and Kinetic Experiments 2

2.2. GC Calibration 4

2.3. Precision of Experiments $\quad 5$

2.4. Data Regression $\quad 5$

3. DEFINITION OF THE REACTION NETWORK

3.1. Identification of Reactions for High Alcohol Formation $\quad 5$

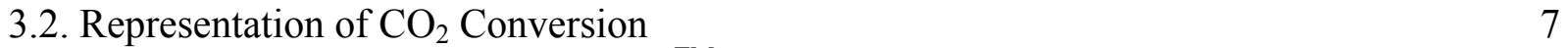

3.3. Reaction Network for the LPMEOH ${ }^{\mathrm{TM}}$ Process 9

4. DEVELOPMENT OF RATE MODELS $\quad 10$

4.1. The Kinetic Experiments, Database and the Procedures for Rate Model Development 10

4.2. Correction for Catalyst Deactivation 11

4.3. Rate Models

5. THE SENSITIVITY OF A RATE MODEL AND ITS EFFECTS ON CATALYST

5.1. The Effect on Error Propagation $\quad 20$

5.2. The Effect on the Rate of Catalyst Aging $\quad 25$

6. LPMEOH $^{\mathrm{TM}}$ WITH WATER INJECTION 26

6.1. Water Injection with Different Syngas Compositions 26

6.2. Does High Water Concentration Suppress Methanol Synthesis? 29

6.3. Catalyst Stability under Water Injection Conditions 29

7. SUMMARY 30

$\begin{array}{ll}\text { APPENDICES } & 32\end{array}$ 


\section{INTRODUCTION}

The Liquid Phase Methanol (LPMEOH $\left.{ }^{\mathrm{TM}}\right)$ process provides an alternative method of producing methanol from synthesis gas (or syngas, a mixture of $\mathrm{H}_{2}$ and $\mathrm{CO}$ ) to the traditional, packed-bedbased gas phase process. In the $\mathrm{LPMEOH}^{\mathrm{TM}}$ reactor, the methanol synthesis catalyst in a powder form is suspended in an inert liquid medium (e.g., hydrocarbon oil). Because of the superior heat transfer characteristics of this slurry medium, the highly exothermic methanol synthesis reaction can be run under essentially isothermal conditions. This enables direct use of coal-derived, unshifted CO-rich syngas. It also allows the reactor to use the stoichiometric feed $\left(\mathrm{H}_{2}: \mathrm{CO}\right.$ around $2: 1$ ), which gives the best thermodynamic conversion as well as a greater reaction rate. This translates into greater reactor productivity and a smaller burden to the recycle loop.

Accurate kinetic models for the $\mathrm{LPMEOH}^{\mathrm{TM}}$ reaction system are essential for the design and optimization of the $\mathrm{LPMEOH}^{\mathrm{TM}}$ process. A reaction network and corresponding rate models had been developed at Air Products long ago to serve these purposes (Table 1).

Table 1: Reactions in the existing reaction network

\begin{tabular}{|l|l|l|}
\hline Product & Reaction & Reaction \# \\
\hline methanol & $\mathrm{CO}+2 \mathrm{H}_{2} \Leftrightarrow \mathrm{CH}_{3} \mathrm{OH}$ & 1 \\
\hline ethanol & $\mathrm{CO}+2 \mathrm{H}_{2}+\mathrm{CH}_{3} \mathrm{OH} \Leftrightarrow \mathrm{EtOH}+\mathrm{H}_{2} \mathrm{O}$ & 2 \\
\hline 1-propanol & $\mathrm{CO}+2 \mathrm{H}_{2}+\mathrm{EtOH} \Leftrightarrow \mathrm{C}_{3} \mathrm{OH}+\mathrm{H}_{2} \mathrm{O}$ & 3 \\
\hline 1-butanol & $\mathrm{CO}+2 \mathrm{H}_{2}+\mathrm{C}_{3} \mathrm{OH} \Leftrightarrow \mathrm{C}_{4} \mathrm{OH}+\mathrm{H}_{2} \mathrm{O}$ & 4 \\
\hline isobutanol & $\mathrm{CO}+2 \mathrm{H}_{2}+\mathrm{C}_{3} \mathrm{OH} \Leftrightarrow \mathrm{IBOH}_{2} \mathrm{H}_{2} \mathrm{O}$ & 5 \\
\hline 1-pentanol & $\mathrm{CO}+2 \mathrm{H}_{2}+\mathrm{C}_{4} \mathrm{OH} \Leftrightarrow \mathrm{C}_{5} \mathrm{OH}+\mathrm{H}_{2} \mathrm{O}$ & 6 \\
\hline DME & $2 \mathrm{CH}_{3} \mathrm{OH} \Leftrightarrow \mathrm{CH}_{3} \mathrm{OCH} \mathrm{H}_{3}+\mathrm{H}_{2} \mathrm{O}$ & 7 \\
\hline methyl acetate & $\mathrm{CO}+2 \mathrm{CH}_{3} \mathrm{OH} \Leftrightarrow \mathrm{MeAc}+\mathrm{H}_{2} \mathrm{O}$ & 8 \\
\hline methyl formate & $\mathrm{CO}+\mathrm{CH}_{3} \mathrm{OH} \Leftrightarrow \mathrm{MeFm}$ & 9 \\
\hline methane & $\mathrm{CO}+3 \mathrm{H}_{2} \Leftrightarrow \mathrm{C}_{1}+\mathrm{H}_{2} \mathrm{O}$ & 10 \\
\hline ethane & $2 \mathrm{CO}+5 \mathrm{H}_{2} \Leftrightarrow \mathrm{C}_{2}+2 \mathrm{H}_{2} \mathrm{O}$ & 11 \\
\hline propane & $3 \mathrm{CO}+7 \mathrm{H}_{2} \Leftrightarrow \mathrm{C}_{3}+3 \mathrm{H}_{2} \mathrm{O}$ & 12 \\
\hline water gas shift & $\mathrm{CO}+\mathrm{H}_{2} \mathrm{O} \Leftrightarrow \mathrm{CO}_{2}+\mathrm{H}_{2}$ & 13 \\
\hline
\end{tabular}

Due to the change in methanol catalysts and expansion of the $\mathrm{LPMEOH}^{\mathrm{TM}}$ process to new reaction regimes, there was a need to improve the existing models. The main objectives included more accurate prediction of $\mathrm{CO}_{2}$ conversion and a more robust methanol synthesis model with respect to the change in space velocity and gas composition. In addition, all models for the side reactions (Reactions 2 to 12) needed to be revamped, since the old models were developed for a methanol catalyst that is no longer in use, and the new catalyst exhibited very different selectivity.

This report documents our efforts to develop improved kinetic models for the $\mathrm{LPMEOH}^{\mathrm{TM}}$ process. The work was based on a standard commerical methanol synthesis catalyst we currently use in the Kingsport commercial $\mathrm{LPMEOH}^{\mathrm{TM}}$ plant. The reactor system was tuned and GCs were calibrated carefully to provide consistent and high-quality kinetic data. A wide range of gas compositions was examined with the help of a gas blending station. A statistical program developed at Air Products (Statistic Studio) was used to carry out data regression and design supplemental kinetic experiments. Additional reaction by-products were identified and 
incorporated into the reaction network. A number of kinetic models for $\mathrm{CO}$ hydrogenation to methanol, from both literature and in-house development, were examined and the best model was selected. $\mathrm{CO}_{2}$ conversion was better modeled by introducing a new reaction $\left(\mathrm{CO}_{2}\right.$ hydrogenation to methanol), along with new models for the water gas shift reaction and all side reactions that involve water formation. Much improvement in model predictability has been obtained with the new reaction network and rate models.

This work involved efforts from both Air Products' liquid phase technology R\&D group (Gian Muraro, X. D. Peng and Bernie Toseland) and process group (Bharat Bhatt, Barry Diamond and Ed Heydorn). Sanjay Mehta and Tom Bzik provided invaluable help with their statistic program and expertise. The work was performed under DOE's Alternative Fuels II Contract (DE-FC2295PC93052).

\section{EXPERIMENTAL}

\subsection{Apparatus and Kinetic Experiments}

The schematic of the reaction system is shown in Figure 1. The reactors were $300 \mathrm{cc}$ stainless steel autoclaves purchased from Autoclave Engineers. All reactions were carried out under slurry phase conditions, consisting of catalyst powders suspended in a slurry fluid (Drakeol 10 hydrocarbon oil). The reaction pressure was controlled by a backpressure regulator (BPR). A tube furnace was used to maintain the reaction temperature. The feed gas was introduced into the reactor through a dip tube. Each reactor was equipped with the factory-standard six-blade, gas-inducing propeller. The stirrer speed was $1,200 \mathrm{rpm}$. Because the reactors operated like an ideal continuous stirred tank reactor (CSTR), the gas composition throughout the reactor was the same as that in the reactor effluent.

The syngas feeds of fixed compositions were supplied through cylinders or a tube trailer. In addition, a syngas blending station was used to provide syngas feeds of various compositions from pure $\mathrm{H}_{2}, \mathrm{CO}$ and $\mathrm{CO}_{2}$ sources. The nominal compositions of various syngas feeds are summarized in Table 2 below. Three of these gases simulated commercial compositions, including Shell gas (CO-rich with low $\mathrm{CO}_{2}$ content, simulating syngas from Shell gasifier), Texaco gas (CO-rich with high $\mathrm{CO}_{2}$ content, simulating syngas from Texaco gasifier) and Kingsport gas (the gas used at the Kingsport $\mathrm{LPMEOH}^{\mathrm{TM}}$ Demonstration Unit). The names for other gases have no practical bearings. 
Figure 1: Schematic of the reactor system

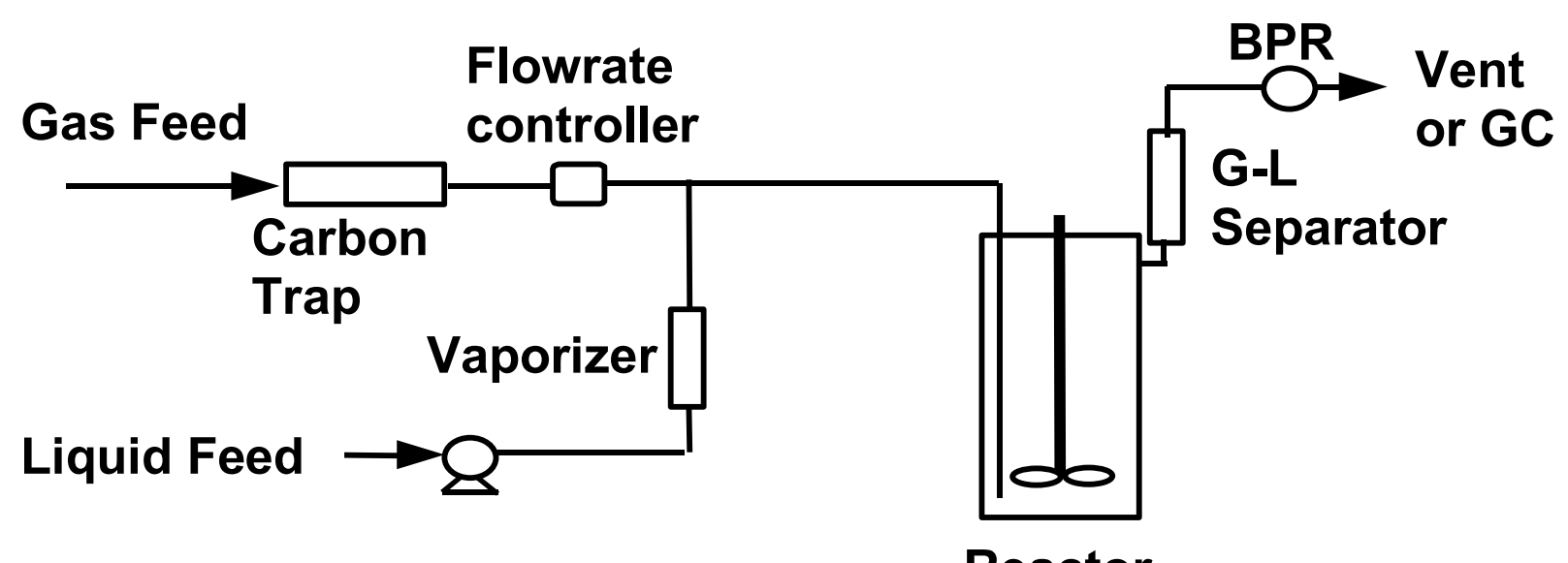

Reactor

Table 2: Nominal compositions of different types of syngas ( $\mathrm{mol} \%$ )

\begin{tabular}{|l|l|l|l|l|}
\hline Gas & $\mathbf{H}_{\mathbf{2}}$ & $\mathbf{C O}$ & $\mathbf{C O}_{\mathbf{2}}$ & $\mathbf{N}_{\mathbf{2}}$ \\
\hline Texaco & 35 & 52 & 12 & 1 \\
\hline Shell & 30 & 66 & 3 & 1 \\
\hline Kingsport & 68 & 22 & 4 & 5 \\
\hline $\mathrm{H}_{2}$-Rich_1 & 73 & 10 & 9 & 8 \\
\hline $\mathrm{H}_{2}$-Rich_3 & 55 & 8 & 7 & 30 \\
\hline $\mathrm{CO}_{2}$-Rich & 71 & 16 & 11 & 2 \\
\hline $\mathrm{CO}_{2}$-Richer & 67 & 13 & 18 & 2 \\
\hline $1: 1$ with low $\mathrm{CO}_{2}$ & 55 & 42 & 2 & 1 \\
\hline $1: 1$ with high $\mathrm{CO}_{2}$ & 49 & 40 & 10 & 1 \\
\hline $\mathrm{CO}$-Rich & 37 & 58 & 4 & 1 \\
\hline $\mathrm{H}_{2}$-Rich & 71 & 20 & 8 & 1 \\
\hline
\end{tabular}

The syngas feed passed through a carbon trap to remove iron and nickel carbonyls prior to entering a reactor. The gas left the reactor through a gas-liquid separator, in which any escaping slurry fluid was collected and drained back to the reactor. The gas-liquid separator temperature was adjusted to be approximately $15-20^{\circ} \mathrm{C}$ above the dew point of the reactor effluent. All lines downstream of the reactor were heat-traced to prevent products such as methanol and water from condensing.

A liquid injection line was used to introduce liquid feeds, including water and methanol, into the reactor. The liquid was pumped by a high-pressure syringe pump. The liquid joined the main syngas feed in a preheater and was fully vaporized prior to entering the reactor.

Reactor inlet syngas and products were analyzed by on-line GCs. Syngas components were quantified by a Hewlett-Packard 5890 GC equipped with dual TCD detectors and packed 
columns. One of the packed columns was used for $\mathrm{H}_{2}$ analysis, with $\mathrm{N}_{2}$ as the carrier gas. The other was used for $\mathrm{CO}, \mathrm{CO}_{2}$ and $\mathrm{N}_{2}$, as well as methanol and DME analysis. Organic products, including methanol and by-products (oxygenates and hydrocarbons), were analyzed by another Hewlett-Packard 5890 GC with a FID detector and $0.53 \mathrm{~mm}$ I.D. x $15 \mathrm{~m}$ capillary column with a $5 \mathrm{~mm}$ DB-1 film. A second Chrompack CP-Wax 52 CB capillary column in the GC, combined with a TCD detector, performed water analysis. Samples were introduced to GCs by electronically controlled valves. The reactor inlet and exit flowrates were measured with wet test meters.

In a typical LPMEOH ${ }^{\mathrm{TM}}$ kinetic experiment, 10 grams of a powdered methanol catalyst were loaded in the reactor, along with 120 grams of Drakeol 10 hydrocarbon oil. After the system was

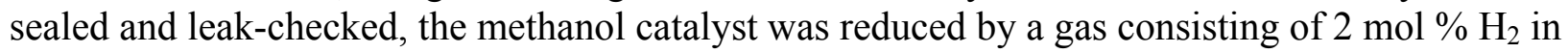
$\mathrm{N}_{2}$. A standard temperature ramp was used for the reduction, which brought the reactor temperature up from room temperature to $240^{\circ} \mathrm{C}$ over a period of 23 hours. The system was then switched to the syngas feed and brought to the reaction conditions within an hour.

All kinetic work was done with our standard methanol catalyst, which is used in our LPMEOH ${ }^{\mathrm{TM}}$ Demonstration Unit in Kingsport. It is a commercially available, $\mathrm{Cu}$-based methanol synthesis catalyst, and was used in its original powdered form.

\subsection{GC Calibration}

The major components in the feed gas and products, $\mathrm{H}_{2}, \mathrm{CO}, \mathrm{CO}_{2}, \mathrm{~N}_{2}$, methanol and DME, were calibrated routinely using certified GC standards. Identification and quantification of oxygenate by-products were accomplished by preparing individual standards. These included methyl formate, ethanol, 2-propanol, methyl acetate, 1-propanol, 2-butanol, ethyl acetate, isobutanol, 1butanol, 2-methyl-1-butanol, 1-pentanol, butyl acetate, 2-methyl-1-pentanol and isobutyl isobutyrate. They all dissolved in 1-octanol that also contained a known amount of methanol. Injection of these standards into the $\mathrm{GC}$ gave the response factors and retention times of these species relative to those of methanol. Once these were established, a master sample containing all these species plus methanol in 1-octanol was prepared for the convenience of later, occasional calibrations. In the routine calibration using methanol standards, if the GC response factor for methanol changed, the factors for all other oxygenates and hydrocarbons were changed accordingly, assuming that the change was related to GC "drift," independent of individual molecules.

Accurate measurement of the water concentration in the reactor effluent is important in developing rate models for water gas shift reaction and side reactions in the LPMEOH ${ }^{\mathrm{TM}}$ reaction system, since 10 of the 13 reactions shown in Table 1 involve either water formation or consumption. Water calibration was achieved by conducting a methanol dehydration experiment in the reaction unit. In this experiment, a methanol dehydration catalyst (e.g., $\gamma$-alumina) was loaded in the autoclave, and methanol feed was introduced into the reactor through the liquid injection pump. The reactor effluent was sent to the water GC. The methanol dehydration reaction $\left(2 \mathrm{CH}_{3} \mathrm{OH} \Leftrightarrow \mathrm{DME}+\mathrm{H}_{2} \mathrm{O}\right)$ had high selectivity $(>99 \%)$ and generated equal molar amounts of DME and water. Since DME calibration was conducted using a certified standard, and therefore had good accuracy, this method provided an accurate, though time-consuming, way for water calibration. 


\subsection{Precision of Experiments}

Many of our kinetic runs were started at so-called baseline conditions: $250^{\circ} \mathrm{C}, 750 \mathrm{psig}, 6000$ GHSV and Shell gas. Therefore, the initial catalyst activities from these runs were used as a measure of the precision of our unit. The results showed that the reactor unit could produce the initial catalyst activity within $\pm 2 \%$ at a $95 \%$ confidence level.

\subsection{Data Regression}

A versatile statistic program (Statistical Studio) developed at Air Products was used for data regression and model development. It had a convenient format to input data, the model formula, and initial values and boundaries of parameters. The regression was quick and robust. The results included conventional parity charts and residual analysis, as well as other useful statistical analyses such as an ANOVA table, confidence level of parameter estimates and the correlation coefficients between parameters. The program was also capable of D-Optimal experimental design. This feature was used to design supplemental experiments in our model development.

\section{DEFINITION OF THE REACTION NETWORK}

\subsection{Identification of Reactions for High Alcohol Formation}

An accurate account of by-products is an important part of kinetic model development for the $\mathrm{LPMEOH}^{\mathrm{TM}}$ process. Table 3 shows the contribution to the carbon, hydrogen and oxygen mass balance of the known by-products in our existing reaction network (all products listed in Table 1 except methanol). The contribution from by-products can be significant, depending on the reaction conditions. For example, they can contribute as much as $3.8 \%$ to the total hydrogen mass balance when the feed gas is CO-rich (e.g., Shell gas) and the space velocity is low (e.g., $3000 \mathrm{GHSV}$ ). The general trend is that a greater amount of by-products is formed under CO-rich syngas and at lower space velocity. Their contribution to the mass balance becomes less significant for $\mathrm{H}_{2}$-rich syngas (Kingsport and $\mathrm{CO}_{2}$-rich gas).

Table 3: The contribution of by-products to mass balance

\begin{tabular}{c|c|c|c|c}
\hline Syngas Type & GHSV & $\begin{array}{c}\text { C-Balance } \\
(\mathbf{\%})\end{array}$ & $\begin{array}{c}\text { H-Balance } \\
\mathbf{( \% )}\end{array}$ & $\begin{array}{c}\text { O-Balance } \\
(\mathbf{\%})\end{array}$ \\
\hline Shell & 3000 & 1.3 & 3.8 & 0.7 \\
\hline Shell & 6000 & 0.9 & 2.6 & 0.5 \\
\hline Kingsport & 6000 & 0.5 & 0.2 & 0.2 \\
\hline Kingsport & 9000 & 0.3 & 0.2 & 0.2 \\
\hline $\mathrm{CO}_{2}$-Rich & 6000 & 0.3 & 0.1 & 0.1 \\
\hline
\end{tabular}

The second incentive for an accurate account of by-products is that most of the reactions that lead to by-products also produce water (see Table 1). If water formation could not be modeled accurately, it would impact the simulation of the water gas shift reaction, which in turn would result in poor prediction of $\mathrm{CO}_{2}$ conversion and methanol formation.

Owing to these considerations, we looked for other by-products that might have been missed in our existing reaction network. The condensed liquid from the reactor effluent was sent for GCMS analysis. Many high alcohols were found, including: 1-butanol, 1-pentanol, 2-methyl-1butanol, 1-hexanol, 2-methyl-1-pentanol, 1-heptanol, 2-ethyl-1-pentaol, 1-octanol, 2-propyl- 
hexanol, 1-nonanol, 2-propyl-1-heptanol, 1-decanol and 2-ethyl-1-nonanol. Among them only the bolded ones were included in the GC analysis and mass balance calculations. Furthermore, only 1-butanol and 1-pentanol were included in the existing reaction network.

To confirm the observation, a gaseous sample was collected from the reactor effluent and sent for GC-MS analysis. The reactor was operating under the LPMEOH ${ }^{\mathrm{TM}}$ baseline conditions $\left(250^{\circ} \mathrm{C}, 750\right.$ psig, $\left.6,000 \mathrm{GHSV}\right)$ using Texaco gas when the sample was taken. The GC-MS results again showed a large number of high alcohols. The significant ones include: 1-pentanol, 1-hexanol, 2-methyl-1-pentanol, 1-heptanol, 2-ethyl-1-hexanol, 1-octanol, 2-nonanol, 2decanol, 2-undecanol and 2-dodecanol.

The significance of these newly detected high alcohols to the mass balance was estimated. The last nine alcohols in the gaseous sample were included in the calculation. The estimate was based on the following two approximations. First, since the total ion intensity of a molecule in a GC-MS spectrum was approximately proportional to its molar quantity, we converted the ion intensity of a species to its molar quantity relative to 1-pentanol. Second, we assumed that the proportion among these alcohols does not vary significantly from one reaction condition to another. This assumption is supported by the observation that the ion intensity ratio of these alcohols in the gaseous sample (one reaction condition) is similar to that in the liquid sample (accumulation of many experiments). Therefore, once we know the concentration of 1-pentanol from an experiment, the quantities of the other nine alcohols can be estimated. The calculated results are shown in Table 4 for three different reaction conditions.

Table 4: Estimates of possible concentrations of high alcohols

\begin{tabular}{|c|c|c|c|c|}
\hline Species & $\begin{array}{l}\text { Total Ion } \\
\text { Intensity }\end{array}$ & $\begin{array}{l}\text { Estimated } \\
\text { Concentr. } \\
\text { (ppm) }\end{array}$ & $\begin{array}{l}\text { Estimated } \\
\text { Concentr. } \\
\text { (ppm) }\end{array}$ & $\begin{array}{l}\text { Estimated } \\
\text { Concentr. } \\
\text { (ppm) }\end{array}$ \\
\hline 1-pentanol & 10.5 & $\left(83.9^{\mathrm{a}}\right)$ & $\left(23.3^{b}\right)$ & $\left(4.0^{c}\right)$ \\
\hline 1-hexanol & 8 & 63.9 & 17.8 & 3.0 \\
\hline 2-methyl-1-pentanol & 8 & 63.9 & 17.8 & 3.0 \\
\hline 1-heptanol & 14 & 111.9 & 31.1 & 5.3 \\
\hline 2-ethyl-1-hexanol & 17 & 135.8 & 37.7 & 6.5 \\
\hline 1-octanol & 7 & 55.6 & 15.5 & 2.7 \\
\hline 2-nonanol & 8 & 63.9 & 17.8 & 3.0 \\
\hline 2-decanol & 10 & 79.9 & 22.2 & 3.8 \\
\hline 2-undecanol & 11 & 87.9 & 24.4 & 4.2 \\
\hline 2-dodecanol & 17 & 135.8 & 37.7 & 6.5 \\
\hline Total 9 alcohols & 100 & 798.6 & 222.0 & 38.0 \\
\hline $\begin{array}{ll}\text { Contribution } & \mathrm{C}: \\
\text { to Mass } & \mathrm{H}: \\
\text { Balance } & \mathrm{O}:\end{array}$ & & $\begin{array}{l}0.85 \% \\
2.08 \% \\
0.13 \%\end{array}$ & $\begin{array}{l}0.25 \% \\
0.49 \% \\
0.02 \%\end{array}$ & $\begin{array}{l}0.09 \% \\
0.04 \% \\
0.01 \%\end{array}$ \\
\hline
\end{tabular}

a: $250^{\circ} \mathrm{C}, 750 \mathrm{psig}, 3000 \mathrm{GHSV}$, Shell gas.

b: $250^{\circ} \mathrm{C}, 750 \mathrm{psig}, 6000 \mathrm{GHSV}$, Texaco gas.

c: $250^{\circ} \mathrm{C}, 750 \mathrm{psig}, 6000 \mathrm{GHSV}$, Kingsport gas.

The second column in Table 4 lists the total ion intensities of these nine alcohols, plus that of 1pentanol from the GC-MS analysis of the gaseous sample. The next three columns are estimated concentrations of these alcohols under three different sets of LPMEOH ${ }^{\mathrm{TM}}$ reaction conditions. 
The bottom row of the table shows the contributions from these nine alcohols to total $\mathrm{C}, \mathrm{H}$ and $\mathrm{O}$ mass balances.

Table 4 shows that the contribution of these alcohols to total mass balance is the greatest under CO-rich gas and low-space-velocity conditions ( $3^{\text {rd }}$ column), and the smallest under $\mathrm{H}_{2}$-rich conditions (last column). In the former case, the contributions from these alcohols to total $\mathrm{C}$ and $\mathrm{H}$ mass balances are 0.85 and $2.08 \%$, respectively. This contribution is too significant to be omitted in our kinetic models. In the $\mathrm{H}_{2}$-rich case, the contribution from these alcohols to total mass balance is negligible. However, since our kinetic models will cover all conditions, the formation of these alcohols needs to be part of our model.

The following approach was used to add these high alcohols to the reaction network. Again assuming that the relative amounts of these alcohols are independent of reaction conditions, the nine alcohols can be lumped into one pseudo compound, denoted as Hicohol. The formula of this pseudo compound based on GC-MS analysis is $\mathrm{C}_{8.6} \mathrm{H}_{18.1} \mathrm{OH}$. For mass balance purposes, the following Hicohol formation reaction is added to our $\mathrm{LPMEOH}^{\mathrm{TM}}$ reaction network:

$$
\text { 14 }{ }^{\text {th }} \text { Reaction: } \quad \quad \quad 16.7 \mathrm{H}_{2}+8.6 \mathrm{CO} \rightarrow \text { Hicohol }+7.6 \mathrm{H}_{2} \mathrm{O}
$$

No attempt was made to develop a specific rate model for Hicohol. Table 4 shows that the total concentration of the nine alcohols is approximately ten times the concentration of 1-pentanol. Assuming that this proportion stays the same regardless of the reaction conditions, we can estimate the rate of Hicohol formation by simply multiplying the rate of 1-pentanol formation by a factor of ten.

Hicohol was also added to our experimental mass balance sheet. Better closure in mass balance was observed as a result of this addition, as shown in Table 5 for five runs using Shell and Texaco gases.

Table 5: Effects of Hicohols on mass balance ${ }^{\mathrm{a}}$

\begin{tabular}{|l|l|lll|lcc|}
\hline Feed & SV & \multicolumn{4}{|c|}{ Mass Balance w/o Hicohols } & \multicolumn{3}{|c|}{ Mass Balance with Hicohols } \\
Gas & & C & H & O & C & H & O \\
\hline Shell & 6000 & 98.6 & 98.7 & 98.9 & 99.1 & 100.0 & 99.0 \\
\hline Shell & 3000 & 98.3 & 97.7 & 98.9 & 99.1 & 99.7 & 99.0 \\
\hline Shell & 9000 & 99.1 & 99.3 & 99.3 & 99.4 & 100.0 & 99.4 \\
\hline Texaco & 3000 & 98.3 & 99.1 & 98.6 & 99.0 & 100.4 & 98.6 \\
\hline Texaco & 6000 & 98.7 & 99.5 & 98.9 & 98.9 & 99.9 & 98.9 \\
\hline
\end{tabular}

a: All at $250^{\circ} \mathrm{C}$ and 750 psig.

\subsection{Representation of $\mathrm{CO}_{2}$ Conversion}

One concern with our existing $\mathrm{LPMEOH}^{\mathrm{TM}}$ kinetic model is its consistently low estimate of $\mathrm{CO}_{2}$ conversion. This could result in poor process and economics predictions, especially when the reactor feed contains high concentrations of both $\mathrm{H}_{2}$ and $\mathrm{CO}_{2}$. Since the water gas shift reaction is the only reaction in our existing reaction network that involves $\mathrm{CO}_{2}$ (see Table 1), one would naturally question whether this reaction could adequately represent $\mathrm{CO}_{2}$ formation/consumption in the reaction system. 
To answer this question, Table 6 lists the experimentally measured $\mathrm{CO}_{2}$ consumption rates and (1-Appr.) for the water gas shift reaction (WGS, see Reaction 13 in Table 1) and $\mathrm{CO}_{2}$

hydrogenation reaction $\left(\mathrm{CO}_{2}\right.$ hydr. $)$, which is:

$\mathrm{CO}_{2}+3 \mathrm{H}_{2} \Leftrightarrow \mathrm{CH}_{3} \mathrm{OH}+\mathrm{H}_{2} \mathrm{O}$

Appr. stands for approach-to-reaction-equilibrium. These definitions are:

$$
\begin{aligned}
& \text { Appr. }=\frac{f_{\mathrm{CO} 2} f_{\mathrm{H} 2}}{K_{\mathrm{W}} f_{\mathrm{H} 2} \mathrm{O}_{\mathrm{CO}}} \quad \text { for the water gas shift reaction, and } \\
& \text { Appr. }{ }_{\mathrm{CO} 2}=\frac{f_{\mathrm{MeOH}} f_{\mathrm{H} 2 \mathrm{O}}}{K_{\mathrm{CO} 2} f_{\mathrm{H} 2}^{3} f_{\mathrm{CO} 2}} \quad \text { for the } \mathrm{CO}_{2} \text { hydrogenation reaction }
\end{aligned}
$$

$f$ in Eqs. 2 and 3 stands for fugacity.

Table 6: Experimentally observed $\mathrm{CO}_{2}$ consumption rate and the approach-to-equilibrium for water gas shift and $\mathrm{CO}_{2}$ hydrogenation reactions

\begin{tabular}{|l|l|l|l|l|}
\hline Experiment & Feed Gas & \multicolumn{2}{|c|}{$\begin{array}{c}\text { COnsumption Rate } \\
\text { (mol/kg-hr) }\end{array}$} & \multicolumn{2}{|c|}{ (1-Appr) } \\
\hline 1 & Kingsport & 0.5 & 0.22 & 0.34 \\
\hline 2 & Kingsport & 0.14 & -0.06 & 0.34 \\
\hline 3 & Kingsport & 1.29 & 0.28 & 0.47 \\
\hline 4 & Kingsport & 0.74 & 0.13 & 0.31 \\
\hline 5 & Kingsport & 0.12 & -0.22 & 0.42 \\
\hline 6 & Shell & -1.26 & -0.24 & 0.45 \\
\hline 7 & Shell & -1.35 & -0.12 & 0.55 \\
\hline 8 & Shell & -1.1 & -0.04 & 0.63 \\
\hline 9 & Shell & -1.09 & -0.04 & 0.59 \\
\hline 10 & Shell & -1.11 & -0.02 & 0.51 \\
\hline 11 & $\mathrm{H}_{2}$-Rich_1 & 3.73 & -0.12 & 0.56 \\
\hline 12 & $\mathrm{H}_{2}$-Rich_1 & 4.53 & 0.02 & 0.58 \\
\hline 13 & $\mathrm{H}_{2}$-Rich_3 & 3.45 & 0.03 & 0.50 \\
\hline 14 & $\mathrm{H}_{2}$-Rich_3 & 2.57 & -0.01 & 0.43 \\
\hline 15 & Texaco & -0.46 & 0.02 & 0.49 \\
\hline 16 & Texaco & -0.39 & 0.01 & 0.50 \\
\hline 17 & Texaco & -0.13 & -0.03 & 0.44 \\
\hline 18 & CO $_{2}$-Rich & 3.9 & 0.17 & 0.53 \\
\hline 19 & CO 2 -Rich & 2.53 & 0.02 & 0.47 \\
\hline
\end{tabular}

If water gas shift is the only reaction that forms or consumes $\mathrm{CO}_{2}$, as indicated by the existing reaction network, the sign of the $\mathrm{CO}_{2}$ consumption rate should be opposite the sign of the water gas shift reaction. That is,

$$
\mathrm{R}_{\mathrm{CO} 2}=-\mathrm{R}_{\mathrm{WGS}}
$$

where $\mathrm{R}_{\mathrm{CO} 2}$ and $\mathrm{R}_{\mathrm{WGS}}$ stand for the rate of $\mathrm{CO}_{2}$ consumption and rate of water gas shift, respectively. Although we do not know the rate of the water gas shift reaction without invoking a specific rate model, we can judge the direction of the reaction by looking at (1-Appr.) for the WGS reaction that is based on experimental measurements. Positive (1-Appr.) means that the water gas shift reaction goes forward, and the $\mathrm{CO}_{2}$ consumption rate should be negative. The 
reverse is true if (1-Appr.) is negative. The table shows that the signs of the measured $\mathrm{CO}_{2}$ consumption rate and (1-Appr.) for the water gas shift reaction are the same in many cases. This indicates that the water gas shift reaction is not the only reaction in the system that forms or consumes $\mathrm{CO}_{2}$. Other $\mathrm{CO}_{2}$-related reactions need to be introduced into the reaction network to account for $\mathrm{CO}_{2}$ consumption.

The reaction we added to the $\mathrm{LPMEOH}^{\mathrm{TM}}$ reaction network is $\mathrm{CO}_{2}$ hydrogenation (see Eq. 1). This reaction has been regarded as a separate route of methanol synthesis in the literature. Table 6 shows that the (1-Appr.) for this reaction is positive under all 19 different reaction conditions, indicating that this reaction proceeded in the forward, i.e., $\mathrm{CO}_{2}$ consumption, direction under these conditions. Considering that the existing kinetic model always under-estimates $\mathrm{CO}_{2}$ conversion, it was expected that addition of this reaction to the reaction network should provide the needed degree of freedom for modeling $\mathrm{CO}_{2}$ conversion better.

\subsection{The Reaction Network for the $\mathrm{LPMEOH}^{\mathrm{TM}}$ Process}

With the addition of the Hicohol and $\mathrm{CO}_{2}$ hydrogenation reactions, the updated reaction network now contains 15 reactions. They are summarized in Table 7.

Table 7: Reactions in the updated reaction network

\begin{tabular}{|l|l|l|}
\hline Product & Reaction & Reaction \# \\
\hline methanol & $\mathrm{CO}+2 \mathrm{H}_{2} \Leftrightarrow \mathrm{CH}_{3} \mathrm{OH}$ & 1 \\
\hline ethanol & $\mathrm{CO}+2 \mathrm{H}_{2}+\mathrm{CH}_{3} \mathrm{OH} \Leftrightarrow \mathrm{EtOH}+\mathrm{H}_{2} \mathrm{O}$ & 2 \\
\hline 1-propanol & $\mathrm{CO}+2 \mathrm{H}_{2}+\mathrm{EtOH} \Leftrightarrow \mathrm{C}_{3} \mathrm{OH}+\mathrm{H}_{2} \mathrm{O}$ & 3 \\
\hline 1-butanol & $\mathrm{CO}+2 \mathrm{H}_{2}+\mathrm{C}_{3} \mathrm{OH} \Leftrightarrow \mathrm{C}_{4} \mathrm{OH}+\mathrm{H}_{2} \mathrm{O}$ & 4 \\
\hline isobutanol & $\mathrm{CO}+2 \mathrm{H}_{2}+\mathrm{C}_{3} \mathrm{OH} \Leftrightarrow \mathrm{IBOH}+\mathrm{H}_{2} \mathrm{O}$ & 5 \\
\hline 1-pentanol & $\mathrm{CO}+2 \mathrm{H}_{2}+\mathrm{C}_{4} \mathrm{OH} \Leftrightarrow \mathrm{C}_{5} \mathrm{OH}+\mathrm{H}_{2} \mathrm{O}$ & 6 \\
\hline DME & $2 \mathrm{CH}_{3} \mathrm{OH} \Leftrightarrow \mathrm{CH}_{3} \mathrm{OCH} \mathrm{H}_{3}+\mathrm{H}_{2} \mathrm{O}$ & 7 \\
\hline methyl acetate & $\mathrm{CO}+2 \mathrm{CH}_{3} \mathrm{OH} \Leftrightarrow \mathrm{MeAc}+\mathrm{H}_{2} \mathrm{O}$ & 8 \\
\hline methyl formate & $\mathrm{CO}+\mathrm{CH}_{3} \mathrm{OH} \Leftrightarrow \mathrm{MeFm}$ & 9 \\
\hline methane & $\mathrm{CO}+3 \mathrm{H}_{2} \Leftrightarrow \mathrm{C}_{1}+\mathrm{H}_{2} \mathrm{O}$ & 10 \\
\hline ethane & $2 \mathrm{CO}+5 \mathrm{H}_{2} \Leftrightarrow \mathrm{C}_{2}+2 \mathrm{H}_{2} \mathrm{O}$ & 11 \\
\hline propane & $3 \mathrm{CO}+7 \mathrm{H}_{2} \Leftrightarrow \mathrm{C}_{3}+3 \mathrm{H}_{2} \mathrm{O}$ & 12 \\
\hline water gas shift & $\mathrm{CO}+\mathrm{H}_{2} \mathrm{O} \Leftrightarrow \mathrm{CO}_{2}+\mathrm{H}_{2}$ & 13 \\
\hline Hicohol & $16.7 \mathrm{H}_{2}+8.6 \mathrm{CO}_{2} \Leftrightarrow \mathrm{Hicohol}_{2}+6 \mathrm{H}_{2} \mathrm{O}$ & 14 \\
\hline $\mathrm{CO}_{2}$ hydrogenation & $\mathrm{CO}+3 \mathrm{H}_{2} \Leftrightarrow \mathrm{CH}_{3} \mathrm{OH}+\mathrm{H}_{2} \mathrm{O}$ & 15 \\
\hline
\end{tabular}

This reaction network relates the rates of these reactions to the rates of each product formation as follows:

$$
\begin{aligned}
& \mathrm{R}_{1}+\mathrm{R}_{15}=\mathrm{R}_{\mathrm{MEOH}}+\mathrm{R}_{\mathrm{ETOH}}+\mathrm{R}_{\mathrm{C} 3 \mathrm{OH}}+\mathrm{R}_{\mathrm{IBOH}}+\mathrm{R}_{\mathrm{C} 4 \mathrm{OH}}+\mathrm{R}_{\mathrm{C} 5 \mathrm{OH}}+2 \mathrm{R}_{\mathrm{DME}}+2 \mathrm{R}_{\mathrm{MeAc}}+\mathrm{R}_{\mathrm{MeFm}} \\
& \mathrm{R}_{2}=\mathrm{R}_{\mathrm{ETOH}}+\mathrm{R}_{\mathrm{C} 3 \mathrm{OH}}+\mathrm{R}_{\mathrm{IBOH}}+\mathrm{R}_{\mathrm{C} 4 \mathrm{OH}}+\mathrm{R}_{\mathrm{C} 5 \mathrm{OH}} \\
& \mathrm{R}_{3}=\mathrm{R}_{\mathrm{C} 3 \mathrm{OH}}+\mathrm{R}_{\mathrm{IBOH}}+\mathrm{R}_{\mathrm{C} 4 \mathrm{OH}}+\mathrm{R}_{\mathrm{C} 5 \mathrm{OH}} \\
& \mathrm{R}_{4}=\mathrm{R}_{\mathrm{C} 4 \mathrm{OH}}+\mathrm{R}_{\mathrm{C} 5 \mathrm{OH}} \\
& \mathrm{R}_{5}=\mathrm{R}_{\mathrm{IBOH}}
\end{aligned}
$$


$\mathrm{R}_{6}=\mathrm{R}_{\mathrm{C} 5 \mathrm{OH}}$

$\mathrm{R}_{7}=\mathrm{R}_{\mathrm{DME}}$

$\mathrm{R}_{8}=\mathrm{R}_{\mathrm{MeAc}}$

$\mathrm{R}_{9}=\mathrm{R}_{\mathrm{MeFm}}$

$\mathrm{R}_{10}=\mathrm{R}_{\mathrm{C} 1}$

$\mathrm{R}_{11}=\mathrm{R}_{\mathrm{C} 2}$

$\mathrm{R}_{12}=\mathrm{R}_{\mathrm{C} 3}$

$\mathrm{R}_{14}=\mathrm{R}_{\text {Hicohol }}$

$\mathrm{R}_{15}-\mathrm{R}_{13}=\mathrm{R}_{\mathrm{CO} 2}$

Eqs. 4 to 17 show that most of the reaction rates in the network can be directly related to the rate of product formation. The exceptions are Reactions 1,13 and 15. These three reactions have only two independently measurable products: methanol and $\mathrm{CO}_{2}$. The method we selected to handle this problem was as follows. First, the measured $\mathrm{CO}_{2}$ consumption rate, $\mathrm{R}_{\mathrm{CO} 2}$, was fit to Eq. 17 to develop the rate models for water gas shift and $\mathrm{CO}_{2}$ hydrogenation reactions. The rate model for $\mathrm{CO}_{2}$ hydrogenation, $\mathrm{R}_{15}$, was then used, along with the other measured rates in Eq. 4, to develop the rate model for $\mathrm{CO}$ hydrogenation to methanol, $\mathrm{R}_{1}$, the most important rate model for the $\mathrm{LPMEOH}^{\mathrm{TM}}$ reaction system.

\section{DEVELOPMENT OF RATE MODELS}

\subsection{The Kinetic Experiments, Database and the Procedures for Rate Model Development}

The kinetic data were collected, and the rate models were developed in stages. In the first stage, the experiments were arranged around commercially relevant conditions. Syngas feeds of various compositions were used (see Table 2). Three of them simulated commercial compositions, including Shell gas (CO-rich with low $\mathrm{CO}_{2}$ content, simulating syngas from the Shell gasifier), Texaco gas (CO-rich with high $\mathrm{CO}_{2}$ content, simulating syngas from the Texaco gasifier) and Kingsport gas (the gas used at the Kingsport $\mathrm{LPMEOH}^{\mathrm{TM}}$ Demonstration Unit). Gas compositions with a high $\mathrm{H}_{2} / \mathrm{CO}$ ratio (" $\mathrm{H}_{2}$-Rich_1" and " $\mathrm{H}_{2}$-Rich_3") were used to simulate the cases with high recycle ratios. Gases with both high $\mathrm{H}_{2}$ and $\mathrm{CO}_{2}$ concentrations (" $\mathrm{CO}_{2}$-Rich" and " $\mathrm{CO}_{2}$-Richer") were used to simulate high $\mathrm{CO}_{2}$ conversion cases. Three experiments used water injection, with the Shell gas as the main feed. Each gas composition was examined, nominally, at three reaction pressures $(650,750$ and $1000 \mathrm{psig})$ and three space velocities $(3000,6000$ and $9000 \mathrm{sl} / \mathrm{kg}-\mathrm{hr})$. All experiments were conducted at $250^{\circ} \mathrm{C}$.

The second-stage experiments were based on the D-Optimal design. The data from the first stage experiments were fit to different methanol synthesis rate models (Reaction 1). Once the best candidate model was chosen, a sequential D-Optimal design was conducted to generate supplemental experiments. The conditions for these additional experiments were in the regions where the chosen model was sensitive to the change of reaction conditions and in the regions that were not covered by the first-stage experiments. The new conditions included a gas with a $\mathrm{H}_{2}$ :CO ratio of about 1 with low $\mathrm{CO}_{2}$ content ("1:1 with low $\mathrm{CO}_{2}$ "), a gas with a $\mathrm{H}_{2}$ : $\mathrm{CO}$ ratio of about 1 with high $\mathrm{CO}_{2}$ content ("1:1 with high $\mathrm{CO}_{2}$ ") and two other gases shown in the table as 
"CO-rich" and " $\mathrm{H}_{2}$-Rich." These four types of syngas were tested at $250^{\circ} \mathrm{C}$ and ca. $900 \mathrm{psig}$ with very high space velocity (from 18,000 to 24,000 ) to meet the D-Optimal design. The rate models for all 15 reactions were then developed using the data from the first- and second-stage experiments, i.e., all the data at $250^{\circ} \mathrm{C}$.

The temperature-dependent data were collected in the third stages. That is, experiments were conducted using Shell, Texaco and Kingsport gases at 230, 240 and $250^{\circ} \mathrm{C}$. For each gas and temperature, two to three space velocities were used. The models developed in the second stage were then fit to the data from all three stages to obtain the temperature-dependency of all parameters, i.e., activation energies for the rate constants and heats of adsorption for the adsorption equilibrium constants.

The conditions and results from these kinetic experiments are summarized in Appendices 1 to 6: Appendix 1 for the conditions of these experiments; Appendix 2 for the results relevant to the CO-hydrogenation reaction (Reaction 1); Appendix 3 for the results relevant to water gas shift and $\mathrm{CO}_{2}$ hydrogenation reactions (Reactions 13 and 15); and Appendices 4 to 6 for the results relevant to all by-product formation. All of the results can be related to each other through the Run ID \#.

\subsection{Correction for Catalyst Deactivation}

The data from these kinetic experiments were collected over periods as long as 420 hours on stream. Because catalyst aging was significant in these experiments, all data were corrected for aging before they were used for rate model development. The procedures are as follows:

For experiments at a given temperature, the catalyst aging for a specific reaction, $i$, is modeled by the exponential decay model, i.e.,

$$
\mathrm{k}_{\mathrm{i}}=\mathrm{k}_{\mathrm{i}}^{0} \exp \left(-\alpha_{i} \mathbf{t}\right)=\mathrm{k}_{\mathrm{i}}^{0} \mathrm{a}_{\mathrm{i}}
$$

where $\mathbf{t}$ is the on-stream-time, $\alpha_{i}$ stands for the aging rate of the functionality in the catalyst responsible for Reaction $i, \mathrm{k}_{\mathrm{i}}{ }^{2}$ and $\mathrm{k}_{\mathrm{i}}$ are the rate constant in the rate model for Reaction $i$ at time zero and $\mathbf{t}$, respectively, and $\mathrm{a}_{\mathrm{i}}$ is called aging factor defined as

$$
\mathrm{a}_{\mathrm{i}}=\exp \left(-a_{i} \mathbf{t}\right)
$$

Physically, the aging factor means the percent of activity left for Functionality $i$ in the catalyst at time $\mathbf{t}$ with respect to the activity of the fresh catalyst.

For Reaction $i$, the rate model can be generally written as

$$
\mathrm{R}_{\mathrm{i}}=\mathrm{k}_{\mathrm{i}} \Phi_{\mathrm{i}}=\mathrm{k}_{\mathrm{i}}^{0} \mathrm{a}_{\mathrm{i}} \Phi_{\mathrm{i}}
$$

where $\Phi_{\mathrm{i}}$ stands for the rest part of the rate model except the rate constant. The aging correction we made is to convert the measured rate for Reaction $i$ corresponding to an aged catalyst, $\mathrm{R}_{\mathrm{i}}$, to the rate corresponding to the fresh catalyst, $\mathrm{R}_{\mathrm{i}}{ }^{\mathrm{i}}$, by

$$
\mathrm{R}_{\mathrm{i}}^{0}=\mathrm{R}_{\mathrm{i}} / \mathrm{a}_{\mathrm{i}}=\mathrm{k}_{\mathrm{i}}^{0} \Phi_{\mathrm{i}}
$$

$\mathrm{R}_{\mathrm{i}}{ }^{0}$ was used for development of rate models. 
The aging factor, $\mathrm{a}_{\mathrm{i}}$, was determined as follows: All kinetic experiments were started with the so-called baseline conditions: Shell gas, $750 \mathrm{psig}, 250^{\circ} \mathrm{C}$ and $6000 \mathrm{SV}$. These conditions were repeated periodically, alternating with examinations of other kinetic conditions. For each of the data points under the baseline conditions, the rate constant, $\mathrm{k}_{\mathrm{i}}$, can be calculated for a chosen rate model for Reaction $i$, and the aging rate, $a_{i}$, can be estimated by fitting the $\mathrm{k}_{\mathrm{i}}$-vs.-t data to Eq. 18 . Finally, the aging factor, $a_{i}$, is calculated from Eq. 19. This method allows one to estimate the aging factor based on one set of reaction conditions (the baseline conditions). Therefore, even if the rate model is not very robust against varying reaction conditions, its effect on calculating $\mathrm{k}_{\mathrm{i}}$, and therefore $a_{i}$ and $\mathrm{a}_{\mathrm{i}}$, is minimized.

Since the aging rate for Reaction $i$ is calculated from the rate constant in a chosen rate model for the reaction, an iterative process was needed for aging correction. First, prior to the development of any new rate models, the aging rate was calculated based on the rate constant from the existing methanol synthesis model. This aging rate was used to correct the measured rates for all the reactions in that specific experiment. Once a new rate model was developed, the rate constant for this new model was calculated using the original (non-aging-corrected) data, followed by estimating the aging rate for the reaction based on this new model. If the new aging rate differed from the one estimated in the first step, all raw data were corrected for aging using the new aging rate. These corrected data were then used to re-estimate the parameters in the chosen rate model. The steps were repeated until the aging rate converged.

One alternative to the above approach is to include the time-dependent terms explicitly in the rate. This alternative approach could be advantageous in that the models may simulate catalyst aging more accurately. The disadvantage is that this approach requires a built-in catalyst-aging model. A poor choice of aging model could decrease the quality of the kinetic models. Furthermore, it requires a fixed catalyst-aging rate for a given reaction for all experiments, which is in contrast to what we have observed. The aging rate for a given reaction varied from one experiment to another, possibly due to the dependence of aging on reaction conditions and/or possibly random reactor artifacts (e.g., losing catalyst to the walls of the reactor). The current approach allows variation in the aging rate. Moreover, although the exponential decay model was used in the current approach, it was used mainly as a tool for data interpolation, rather than as a built-in catalyst-aging model. In fact, it was used sometimes for different sections of an experiment when all the data could not be fit together well by the decay model.

\subsection{The Rate Models}

\section{Reaction of CO Hydrogenation to Methanol}

The rate models for all 15 reactions in the $\mathrm{LPMEOH}^{\mathrm{TM}}$ reaction network were developed by fitting the rate expressions to Eqs. 4 to 17. The rate model for the most important reaction in the system, $\mathrm{CO}$ hydrogenation to methanol or $\mathrm{R}_{1}$, was developed by screening our own rate models, including the existing model, and the models in the literature. A model from the literature showed the best fit and was chosen to represent the reaction. The comparison of the rate from experimental measurements and model predictions is shown in Figure 2, along with the simulated rates from the existing model. The figure shows that significant improvement in agreement is achieved. The data used for developing this model are summarized in Appendix 2. 
Figure 2: Comparison of experimental and simulated $\mathrm{CO}$ hydrogenation rates for new and existing rate models

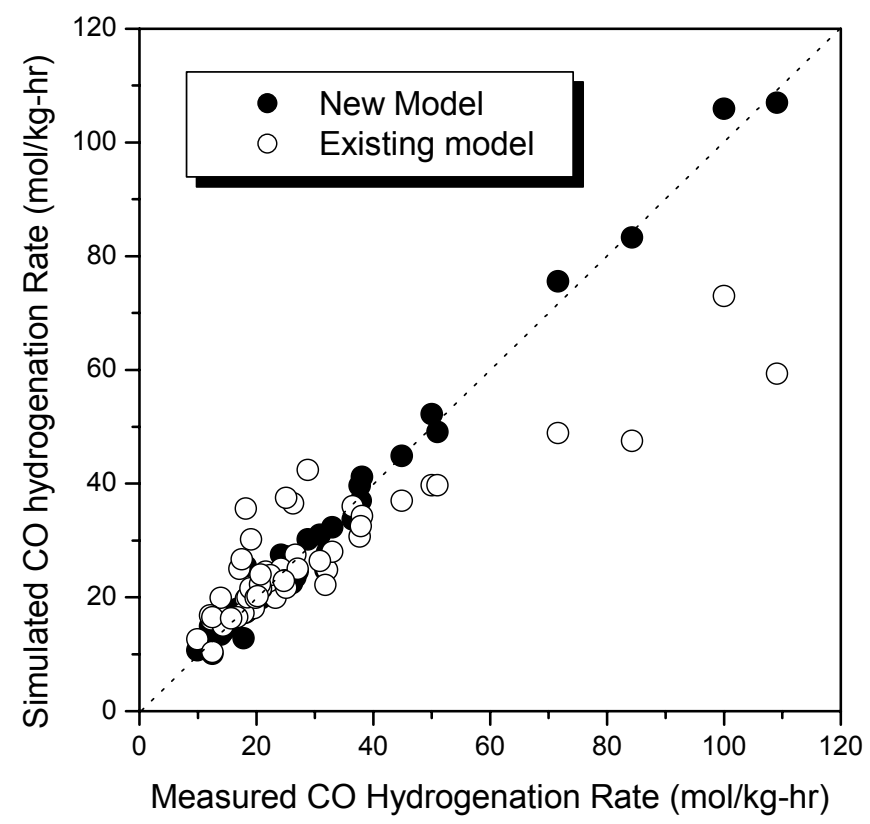

\section{Reactions of Water Gas Shift and $\mathrm{CO}_{2}$ Hydrogenation to Methanol}

As discussed previously, the rate models for the water gas shift reaction (Reaction 13 in Table 7) and the reaction of $\mathrm{CO}_{2}$ hydrogenation to methanol (Reaction 15) were developped together using Eq. 17. The data related to the development of these models are summarized in Appendix 3 . Both rate models have the power-law form, multiplied by a (1-appr.) term. The approach-toequilibrium for the water gas shift reaction in some of the experiments was close to $100 \%$ (see Appendix 3). Since the data from these experiments would introduce great errors to data regression, the runs that with $A p p r_{W G S}$ greater than $90 \%$ were excluded in the development of the models for these two reactions.

Figure 3 compares the $\mathrm{CO}_{2}$ consumption rates calculated from the rate models for all data points with those measured from the experiments. The calculations from both new models and existing models are shown. The fitting is greatly improved with the new models. Introduction of the reaction of $\mathrm{CO}_{2}$-hydrogenation-to-methanol played an important role in this improvement. 
Figure 3: Comparison of experimental and simulated $\mathrm{CO}_{2}$ consumption rates for new and existing rate models

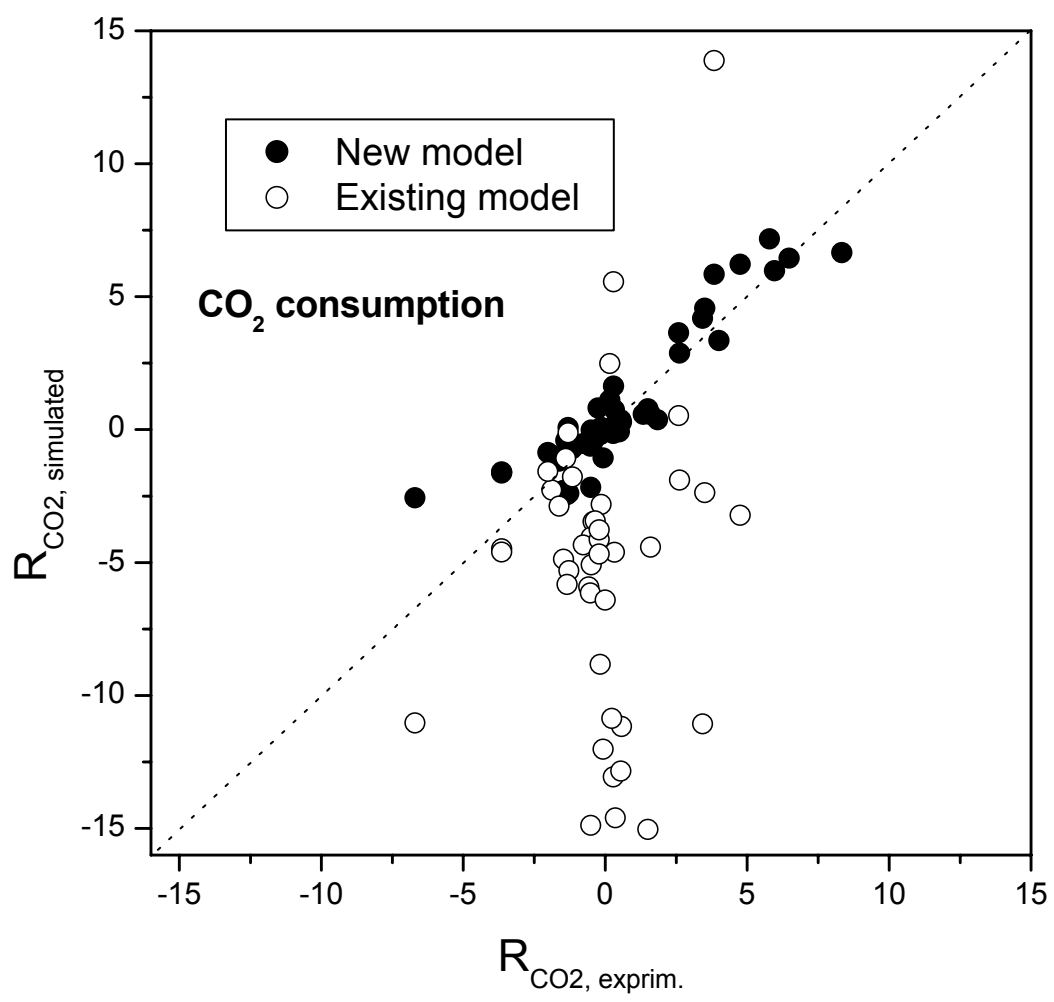

\section{By-Product Formation}

The rate models for all the reactions that lead to by-product formation were developed by empirical regression using the data summarized in Appendices 4 to 6 . All of the rate models are in power-law form. The model for Reaction 9, methyl formate formation, also contains a (1appr.) term. No special rate model was developed for Hicohol formation. Based on the observation discussed in Section 3.1, the rate of Hicohol formation is approximated as 10 times the rate of 1-pentanol formation. That is,

$\mathrm{R}_{14}=10 \mathrm{R}_{6}$

Figure 4 displays the experimental results verses those from the model predictions. Also depicted in the figure are the simulated results from the existing models. In all cases, considerable improvement was achieved. 
Figure 4: Comparison of experimental and simulated rates for new and existing rate models
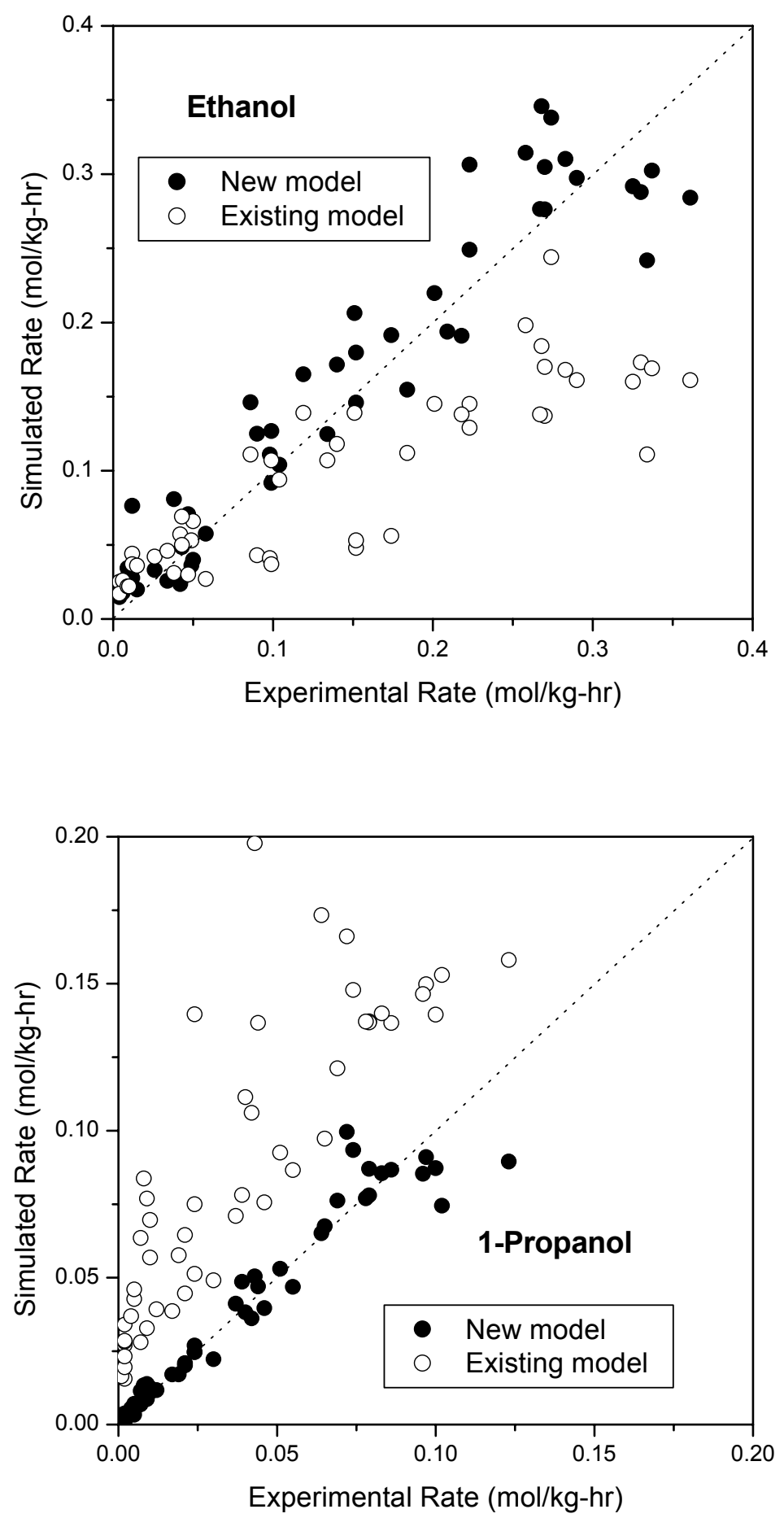

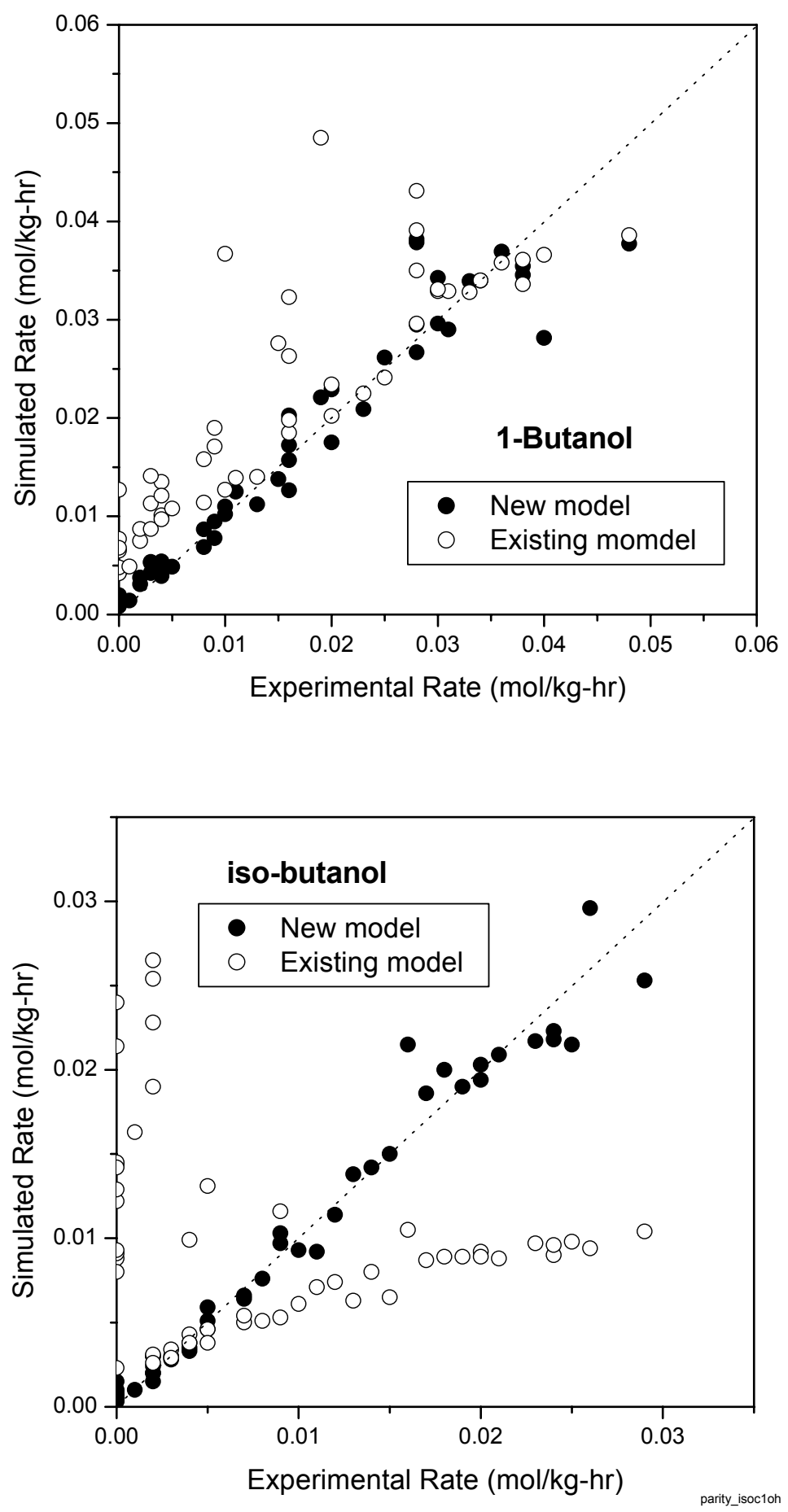

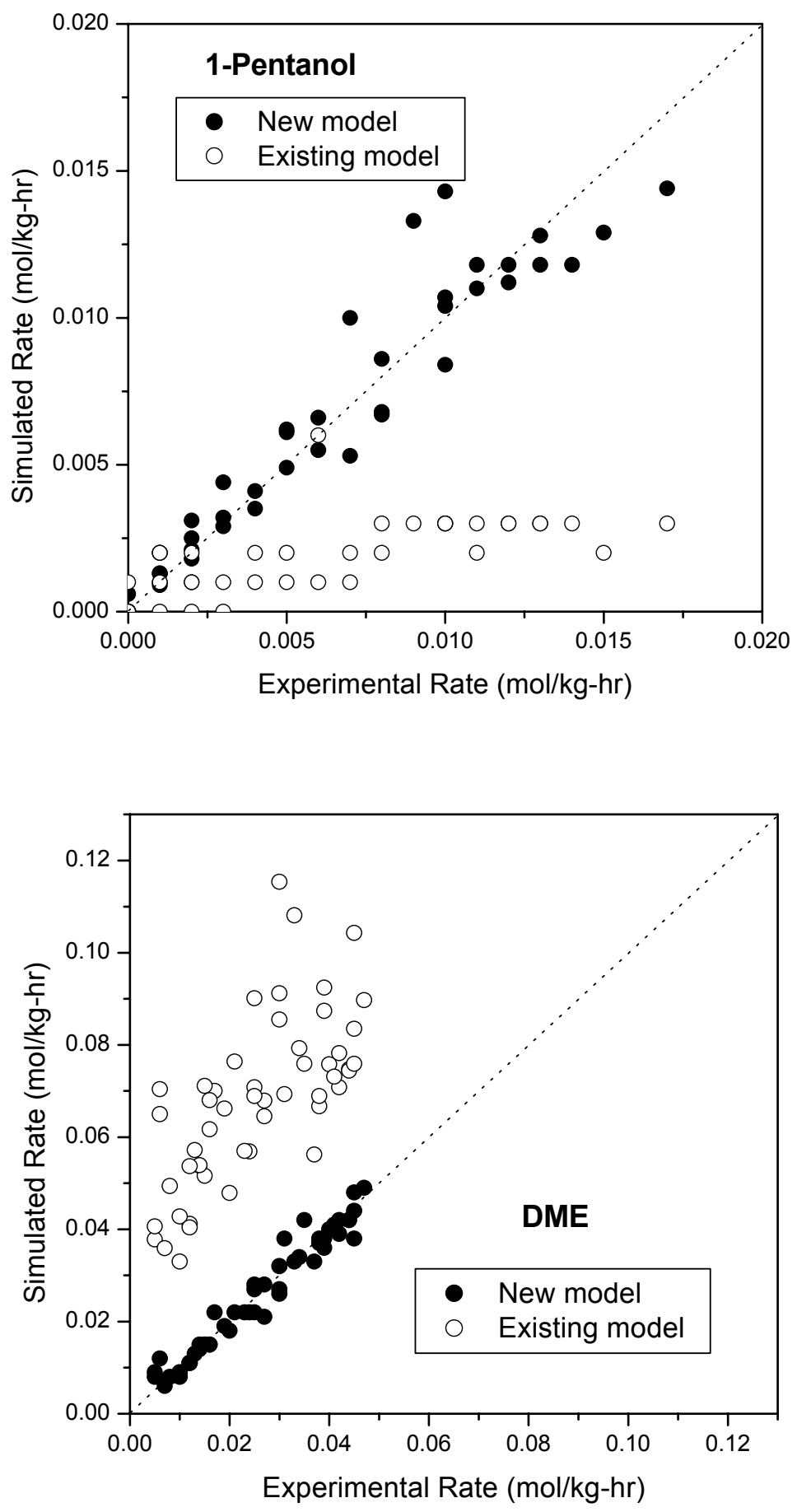

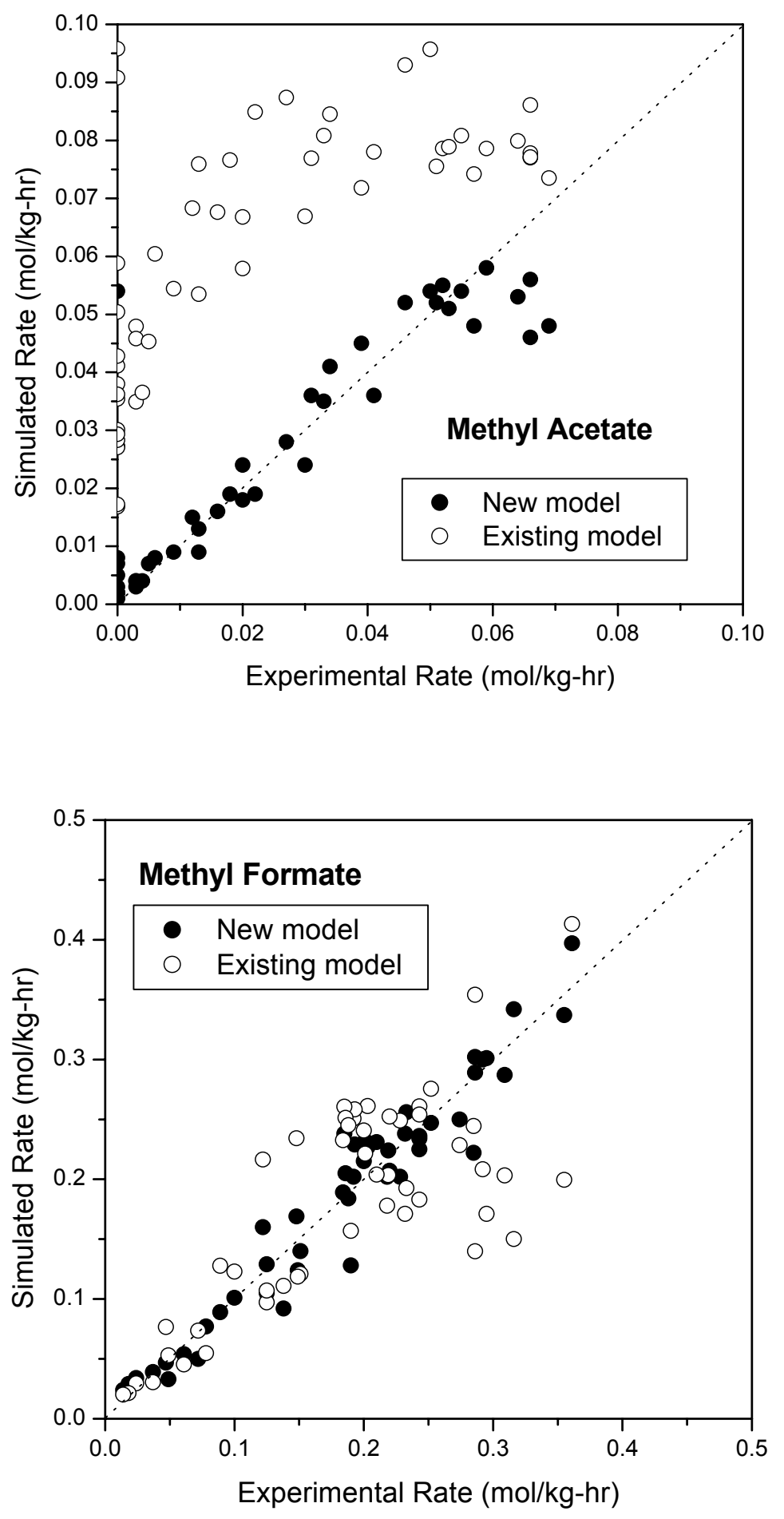

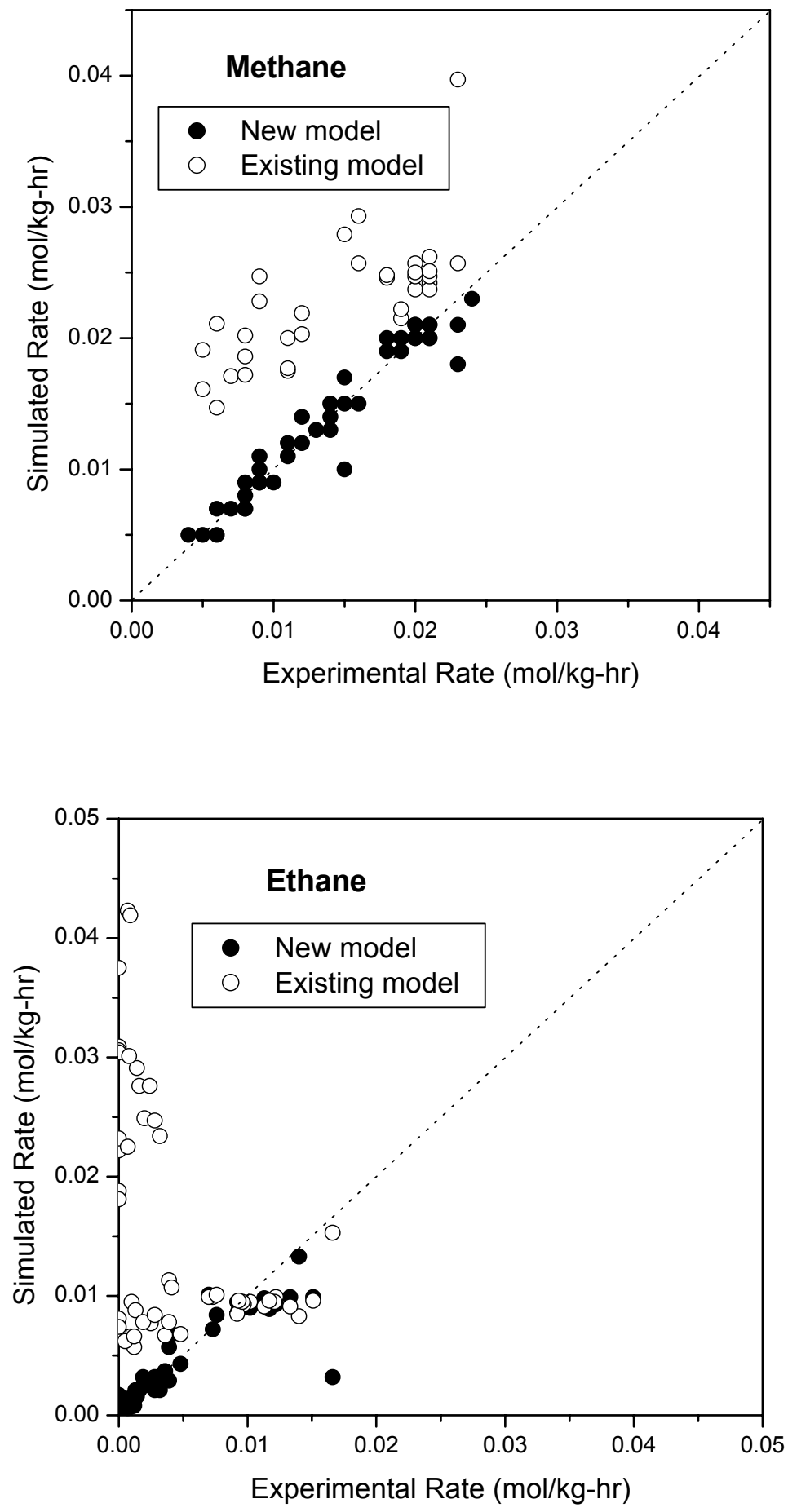


\section{THE SENSITIVITY OF A RATE MODEL AND ITS EFFECTS ON CATALYST LIFE STUDY}

\subsection{The Effect on Error Propagation}

In our typical catalyst life study, the rate of catalyst deactivation was estimated by plotting the relative pre-exponential factor, $\eta$, as a function of time on stream. (For life studies conducted at constant temperature, this is equivalent to the relative rate constant as a function of time on stream.) There are two reasons for this approach. First, the pre-exponential factor, or rate constant, is more sensitive to the change in catalyst activity than other indicators such as conversion and productivity. Second, it does not change, in principle, with the variations in the reaction conditions, therefore, making the life study less dependent on maintaining a set of constant reaction conditions. It also makes possible the comparison of catalyst aging under different conditions. However, using the pre-exponential factor, or rate constant, for catalyst life studies has its own issues. This is illustrated below.

Figure 5 displays a set of life data from the LPMEOH ${ }^{\mathrm{TM}}$ Demonstration Unit at Kingsport. In each of the three periods, the reaction conditions were kept constant. The relative $\eta$ for the methanol synthesis reaction was calculated using both new and existing rate models for Reaction 1. Two observations can be made. First, the data derived from the new model are more scattered than those from the existing model. For most of the data points, the data scatter in the same manner, but by greater magnitudes for the new model. The standard deviation (SD) for the new model is greater by a factor of 2 to 3 . Second, the aging rate (relative $\eta$ vs. time on stream) is greater for the new model.

Figure 5: Kingsport plant catalyst life data from different kinetic models

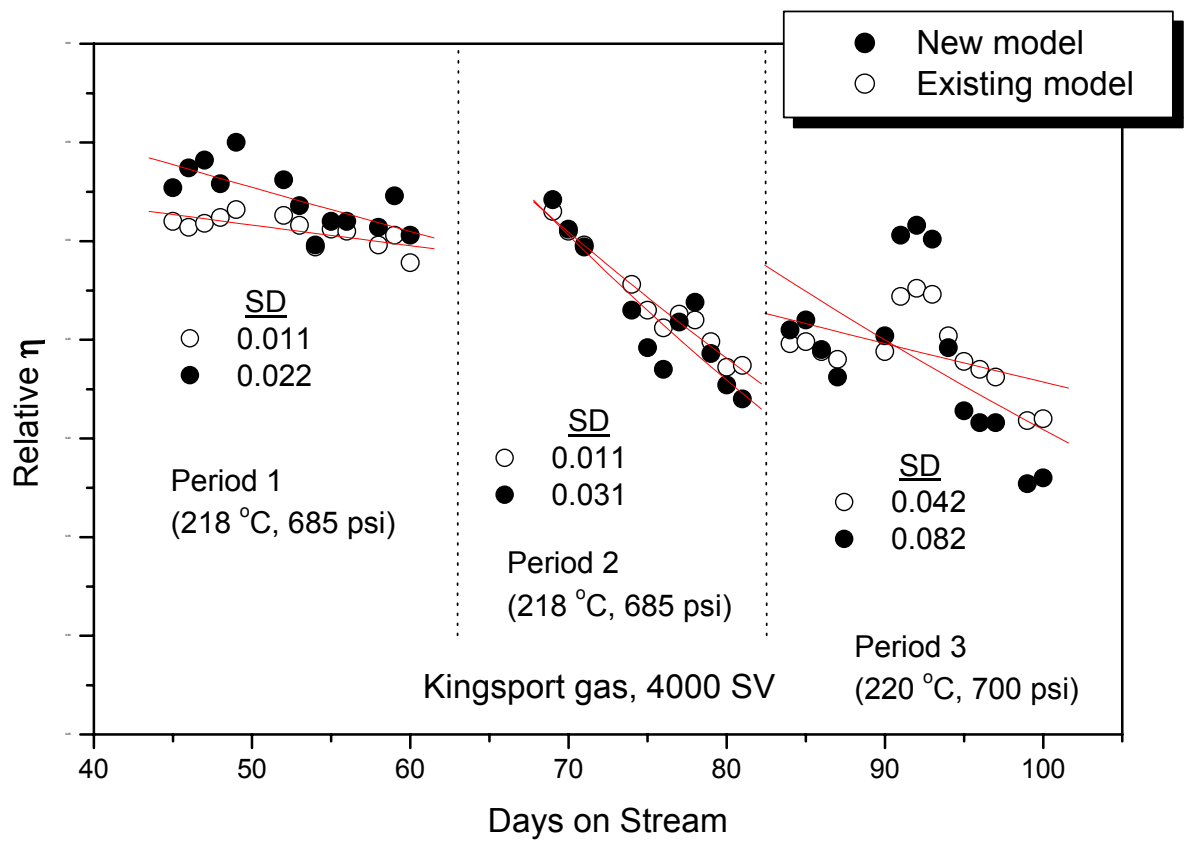


Greater scatter from the new model is puzzling considering that the model fits the methanol synthesis data much better than does the existing model over a wide range of conditions (see Figure 2). The question then is whether the new model fits the data better than the existing model under the specific conditions used for the Kingsport life study. To answer this question, the data from our kinetic study under the Kingsport gas conditions are plotted in Figure 6. The conditions range from 230 to $250^{\circ} \mathrm{C}, 650$ to 750 psig and 3000 to $9000 \mathrm{GHSV}$. It can be seen that the new model still fits the data better than the existing model under Kingsport gas conditions. Therefore, one cannot conclude that the greater scatter for the new model results from its being less robust than the existing model under Kingsport gas conditions.

Figure 6: Comparison of simulated and experimental methanol synthesis rates for different kinetic models

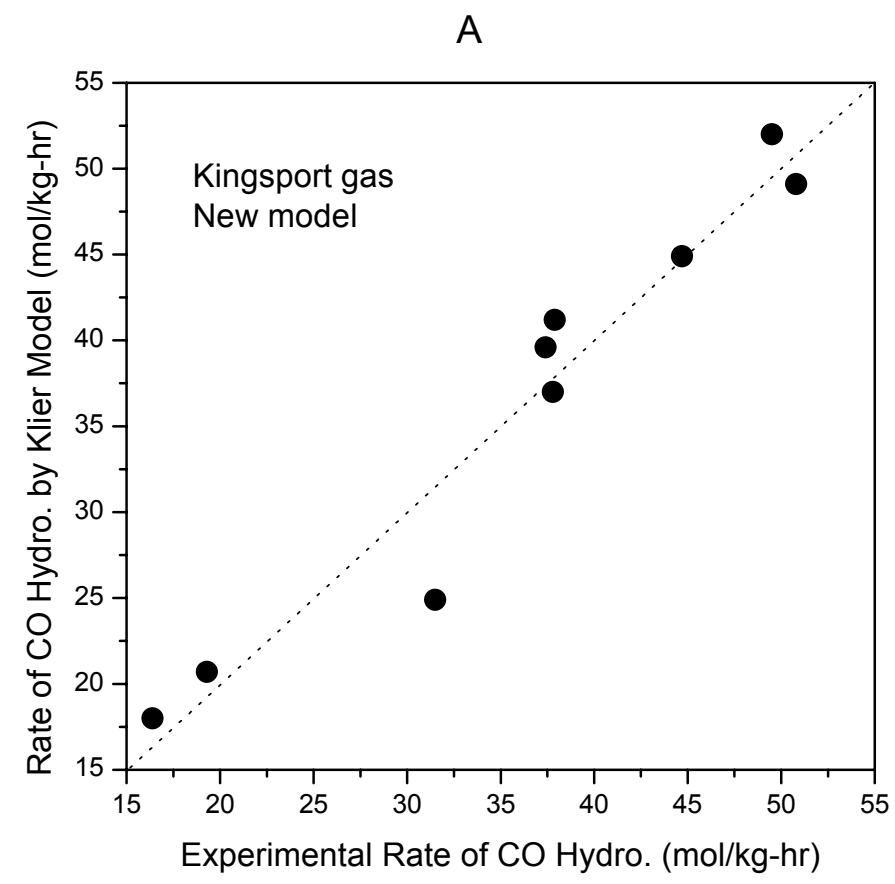




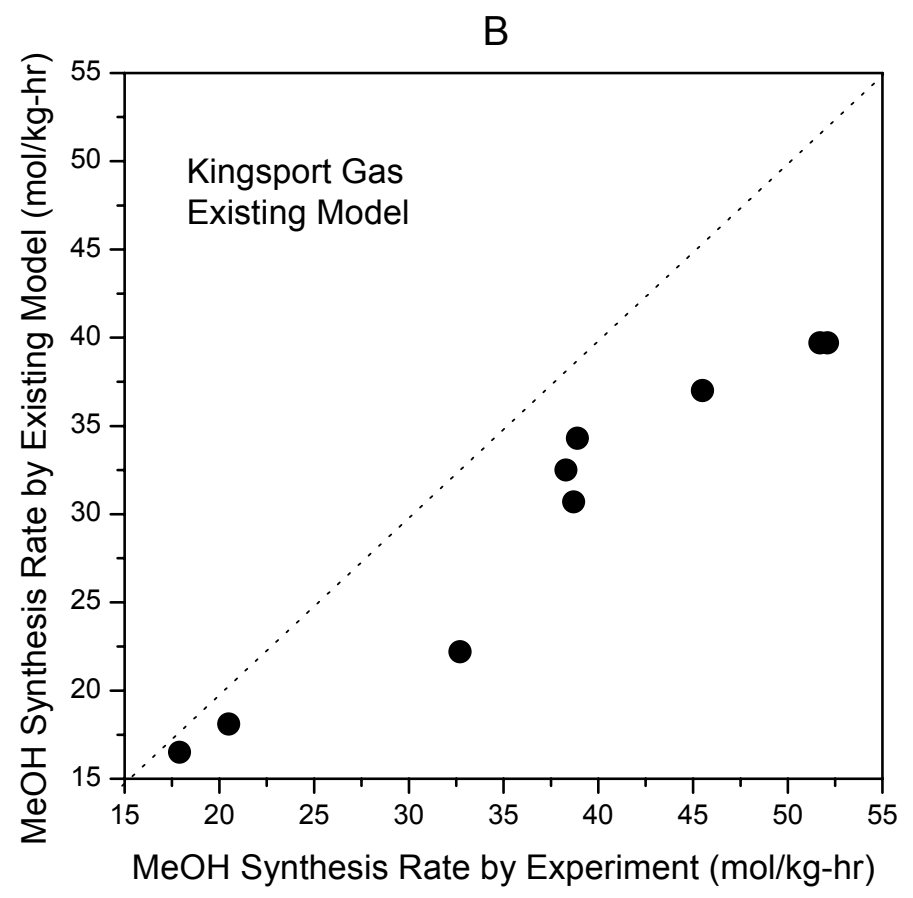

Mathematically, a more robust model with more than one parameter does not guarantee that any one of the parameters in the model should be less scattered when it is back calculated from the experimental data. This is true because fit to data is a collective effect of all parameters. The data can be well fit, but the inherent scatter in the parameters could be large. This is especially true when there are strong correlations among the parameters. Statistically, this inherent scatter is described as the precision with which the parameter is obtained from the regression, and is quantified by the confidence interval of the parameter.

For the new model, the correlation between the pre-exponential factor and the other four parameters is minimal, $0.05,0.04,-0.04$ and -0.04 , respectively. The $95 \%$ confidence interval is $\pm 2.5 \%$ for all conditions and $\pm 12.4 \%$ for the Kingsport conditions. In contrast, the $95 \%$ confidence interval for the existing model is $\pm 5.3 \%$ for all conditions and $\pm 20.8 \%$ for the Kingsport conditions. It is therefore concluded that the greater scatter for the new model shown in Figure 5 cannot be attributed to the precision with which the pre-exponential factor in the new model was obtained.

The two possible causes analyzed above can be further excluded by the following two examples. Both examples use the pre-exponential factors calculated from lab experimental data points, and therefore contain the two factors discussed above (model robustness and parameter precision). The first example is a life study conducted in the lab reactor under Kingsport gas conditions (Figure 7). Similar data scatter is observed from both new and existing models. 
Figure 7: Catalyst life data from the lab LPMEOH ${ }^{\mathrm{TM}}$ experiment under Kingsport gas conditions for different kinetic models

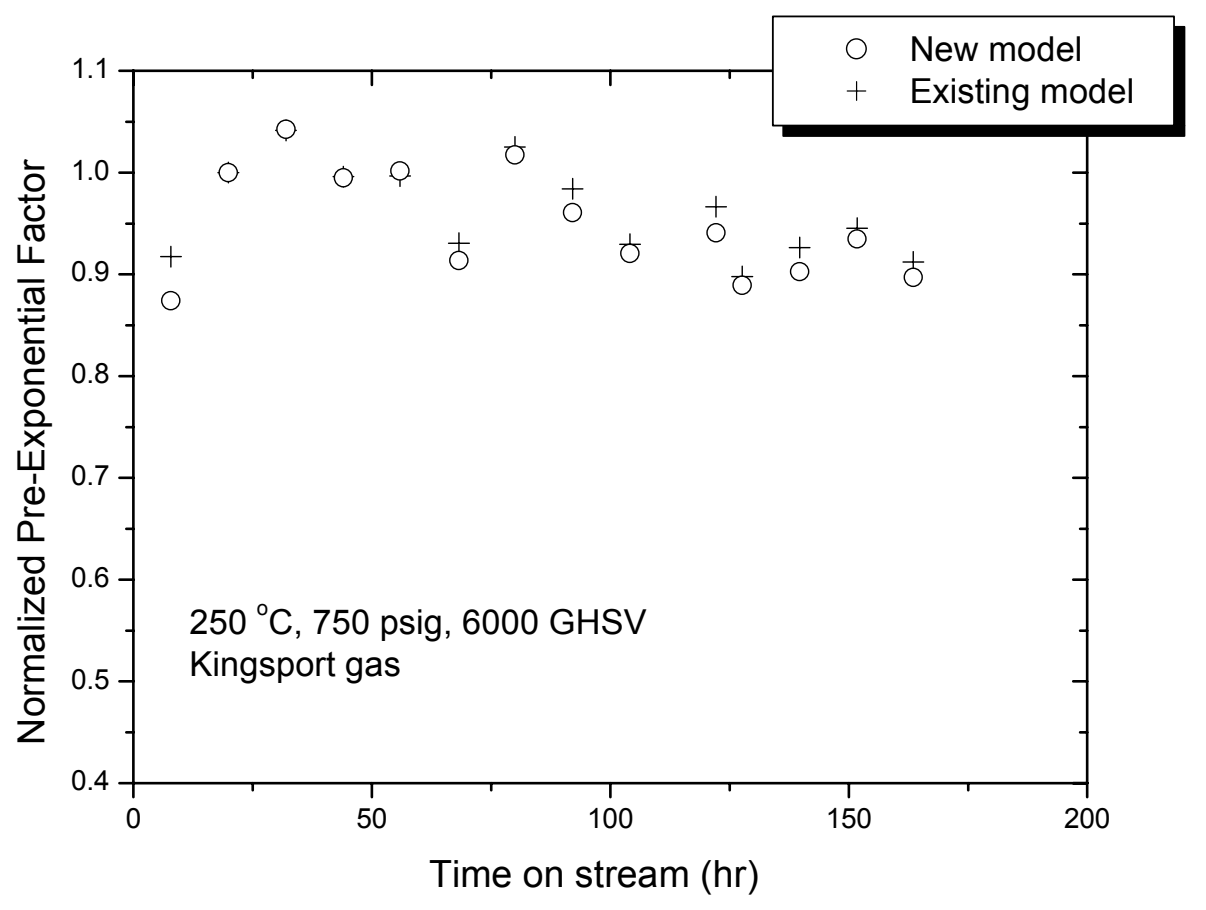

The second example is the pre-exponential factor calculated from the two kinetic models using our lab kinetic data under Kingsport gas conditions. As shown in Table 8, the standard deviation from the new model is smaller than that from the existing model.

Table 8: Relative pre-exponential factor under Kingsport gas conditions

\begin{tabular}{|l|c|c|c|c|c|}
\hline & & & & \multicolumn{2}{|c|}{$\eta$} \\
\hline Run & GHSV & P, psig & T, ${ }^{\mathbf{C}}$ C & New Model & Existing Model \\
\hline 1 & 5792 & 755.9 & 250 & 0.95 & 1.26 \\
\hline 2 & 9026 & 758.9 & 249.9 & 0.95 & 1.30 \\
\hline 3 & 2808 & 754.7 & 250.2 & 0.93 & 1.13 \\
\hline 4 & 5790 & 651.6 & 250.1 & 1.26 & 1.47 \\
\hline 5 & 2820 & 652.6 & 250 & 0.91 & 1.08 \\
\hline 6 & 9024 & 756.4 & 240.1 & 1.03 & 1.31 \\
\hline 7 & 5792 & 758 & 239.8 & 0.92 & 1.13 \\
\hline 8 & 9024 & 749.4 & 230.2 & 1.00 & 1.23 \\
\hline 9 & 5792 & 754.5 & 230.1 & 1.02 & 1.18 \\
\hline \multicolumn{7}{l}{ Standard deviation (\%) } & 0.108 & 0.120 \\
\hline
\end{tabular}

Eliminating the two possibilites discussed above led us to look at the third possibility: the measurement errors in the raw data (independent variables in a model such as T, P and gas composition). These errors may propagate differently in different models, causing different degrees of scatter, and can be shown as follows: 
Let us denote a kinetic model as

$$
R=\eta \bullet \Psi
$$

where $\mathrm{R}$ is the measured reaction rate, $\eta$ is the relative pre-exponential factor, and $\Psi$ stands for the remainder of the model. From Eq. 22 one can have

$$
\frac{\Delta \eta}{\eta}=\frac{\Delta R}{R}+\frac{\Delta \Psi}{\Psi}
$$

where $\Delta$ is the errors in $\eta, \mathrm{R}$ and $\Psi$ caused by the measurement errors. For different models, $\Delta \mathrm{R} / \mathrm{R}$ is the same, but $\Delta \Psi / \Psi$ may be different, depending on how sensitively the model responds to the measurement errors. Therefore, $\Delta \eta / \eta$, i.e., the scatter in $\eta$, can be different.

To illustrate this for the Kingsport plant catalyst life data, we created small perturbations in the independent variables (T, P and composition) and calculated how the new and existing models respond to them and how this propagates to the pre-exponential factor. The perturbations were made at the Kingsport plant life study conditions, and the results are shown in Table 9. It can be seen that the calculated variation in $\Psi$ as a function of perturbation of operating conditions (except $\mathrm{CO}_{2}$ concentration) is greater, by a factor of 1.4 to 2 , for the new model than for the existing model; among these perturbations, temperature has the greatest impact. This shows that the new model is more sensitive than the existing model at the given conditions. Any errors (except $\mathrm{CO}_{2}$ concentration) in the raw data will propagate more in the new model, causing greater scatter in the derived pre-exponential factor. We believe that this is the most plausible explanation for the different scatter from the different models shown in Figure 5.

Table 9: Response of different rate models to perturbation

\begin{tabular}{|l|l|l|}
\hline & $\Delta \Psi / \Psi(\%)$ & $\Delta \Psi / \Psi(\%)$ \\
\hline Perturbation & New model & Existing model \\
\hline$+1{ }^{\circ} \mathrm{C}$ & 4.0 & 2.7 \\
\hline$+2{ }^{\circ} \mathrm{C}$ & 8.1 & 5.5 \\
\hline$+2 \mathrm{psi}$ & 0.5 & 0.3 \\
\hline$+4 \mathrm{psi}$ & 1.0 & 0.7 \\
\hline$+0.2 \% \mathrm{H} 2$ & 0.3 & 0.2 \\
\hline$+0.4 \% \mathrm{H} 2$ & 0.6 & 0.5 \\
\hline$+0.2 \% \mathrm{CO}$ & 0.9 & 0.4 \\
\hline$+0.4 \% \mathrm{CO}$ & 1.9 & 0.8 \\
\hline$+0.2 \% \mathrm{CO} 2$ & 0 & 0.2 \\
\hline$+0.4 \% \mathrm{CO} 2$ & 0 & 0.4 \\
\hline
\end{tabular}




\subsection{The Effect on the Rate of Catalyst Aging}

The same sensitivity argument can explain why different rate models can give different aging rates. The simplest case is zero order kinetics. That is, $\mathrm{R}=\eta * \exp (-\mathrm{Ea} / \mathrm{RT})$; the reaction rate is independent of composition and pressure. The aging rate characterized by $\eta$ will be the same as the decrease in the reaction rate for a life study conducted at constant temperature. A second model, $\mathrm{R}=\eta^{*} \Psi$, has other dependence (e.g., composition, pressure). In general, $\Psi$ increases with an increasing concentration of reactants. For a catalyst life experiment conducted under constant conditions ( $\mathrm{T}, \mathrm{P}$, feed flow and composition), as the catalyst ages, $\mathrm{R}$ will decrease, but $\Psi$ will increase. This occurs because the concentration of the reactants in the reactor will increase due to decreased conversion. Therefore, compared to the zero order kinetics, the aging rate characterized by the decrease in $\eta$ from the second model will be greater, since the decrease in $\mathrm{R}$ is the same in both cases. To extend this further, let us assume that we have two different models, $\mathrm{R}=\eta_{1} * \Psi_{1}$ and $\mathrm{R}=\eta_{2} * \Psi_{2}$. If $\Psi_{2}$ responds to the change in reactant concentration more sensitively than does $\Psi_{1}$, one would expect that the aging rate characterized by $\eta_{2}$ would be greater than that by $\eta_{1}$.

A similar argument can be made if a life experiment is conducted in the constant conversion mode by increasing pressure or temperature. If a model responds to $\mathrm{T}$ or $\mathrm{P}$ more sensitively, it would result in a greater catalyst-aging rate. In brief, a more sensitive rate model will give a greater catalyst-aging rate.

As discussed in the last subsection, the new model is more sensitive than the existing model under the Kingsport plant catalyst life run conditions with respect to the change in reactant concentration $\left(\mathrm{H}_{2}\right.$ and $\left.\mathrm{CO}\right)$, temperature and pressure (see Table 9). This explains why the new model gives a greater aging rate than the existing model (see Figure 5).

Note that the sensitivity of a model varies from one region to another. For example, when the calculations similar to those in Table 9 were performed under the conditions using Shell gas, it was observed that the existing model was more sensitive to $\mathrm{T}$ and less sensitive to $\mathrm{CO}_{2}$ than the new model, as opposed to the observations under the Kingsport conditions (see Table 9). The implication of this observation is that, although a catalyst could in reality age at the same rate in two different regions of reaction conditions, the model could yield two different aging rates due to the variation of the model sensitivity. Therefore, if one wants to compare the aging rates in these two regions, the model sensitivity needs to be taken into consideration.

The root cause for different aging rates from different rate models lies in the fact that most rate models may not capture catalyst aging completely in the pre-exponential factor. This could be especially true when the data used for rate model development are affected by catalyst aging, such as in our case. Since the portion of the aging that is captured by the pre-exponential factor likely differs from model to model, different aging rates are expected from different models. 


\section{LPMEOH ${ }^{\mathrm{TM}}$ WITH WATER INJECTION}

One of the commercial applications that $\mathrm{LPMEOH}^{\mathrm{TM}}$ is suited for is the conversion of coalderived syngas to methanol directly, without first shifting it to more $\mathrm{H}_{2}$-rich gas. To balance the $\mathrm{H}_{2}: \mathrm{CO}$ ratio and increase the reactor productivity, water can be injected into the $\mathrm{LPMEOH}^{\mathrm{TM}}$ reactor, where it reacts with $\mathrm{CO}$ over the methanol synthesis catalyst to form $\mathrm{H}_{2}$ and $\mathrm{CO}_{2}$. To better understand this potential application, the effect of water injection on the $\mathrm{LPMEOH}^{\mathrm{TM}}$ process was investigated. The goals included:

1) To determine whether water injection can significantly improve the productivity of the $\mathrm{LPMEOH}^{\mathrm{TM}}$ process;

2) To identify the best water injection conditions;

3) To develop a mechanistic understanding of the effects of water injection;

4) To investigate catalyst stability under water injection conditions.

\subsection{Water Injection with Different Syngas Compositions}

Water injection experiments with different syngas compositions were conducted. The first one used Shell gas as the primary feed. The reaction temperature and pressure were $250^{\circ} \mathrm{C}$ and 750 psig, respectively, and two space velocities, 3000 and $6000 \mathrm{~mol} / \mathrm{kg}$-hr, were used. At each space velocity, the water concentration in the reactor feed stream was increased (to as high as $15 \mathrm{~mol}$ $\%$ ) until the productivity passed a maximum. The results are shown in Figure 8.

Figure 8: Methanol productivity as a function of water injection

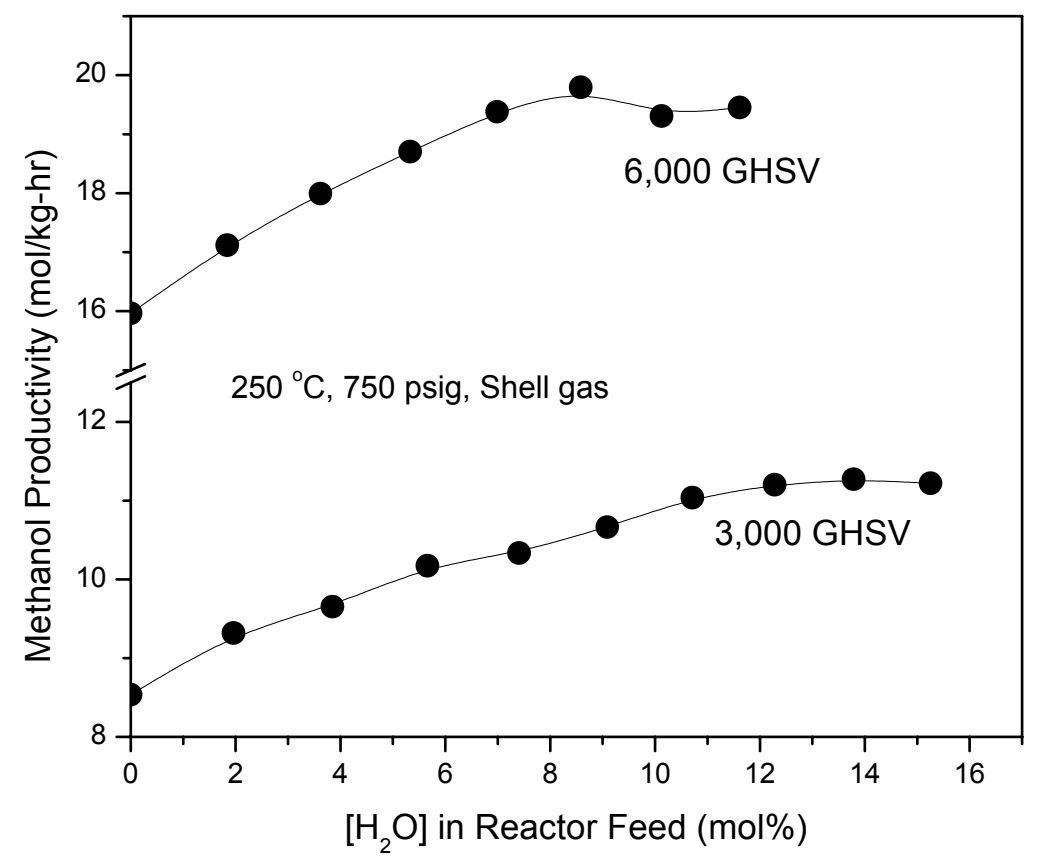

Figure 8 shows that methanol productivity increased with increasing water concentration initially, passed a maximum in each case, and then decreased with increasing water concentration. A significant increase in methanol productivity was obtained in both cases. At the maximum, this increase was 32 and 24\%, respectively, for 3000 and 6000 GHSV. 
Two other syngas feeds were examined. These were Texaco gas (nominally $35 \% \mathrm{H}_{2}, 52 \% \mathrm{CO}$, $12 \% \mathrm{CO}_{2}$, and $\left.1 \% \mathrm{~N}_{2}\right)$ and " $1: 1$ " gas $\left(48 \% \mathrm{H}_{2}, 48 \% \mathrm{CO}, 3 \% \mathrm{CO}_{2}\right.$, and $\left.1 \% \mathrm{~N}_{2}\right)$. Both experiments were conducted at $250^{\circ} \mathrm{C}, 750 \mathrm{psig}$ and $6000 \mathrm{GHSV}$, and the results are shown in Figure 9. No enhancement in productivity was observed in the Texaco gas case. The enhancement in the 1:1 gas case was small, and quickly turned to negative as the water concentration in the feed increased. This clearly indicates that the effect of water injection depends on the feed gas composition.

Figure 9: The effect of water injection on $\mathrm{LPMEOH}^{\mathrm{TM}}$ productivity

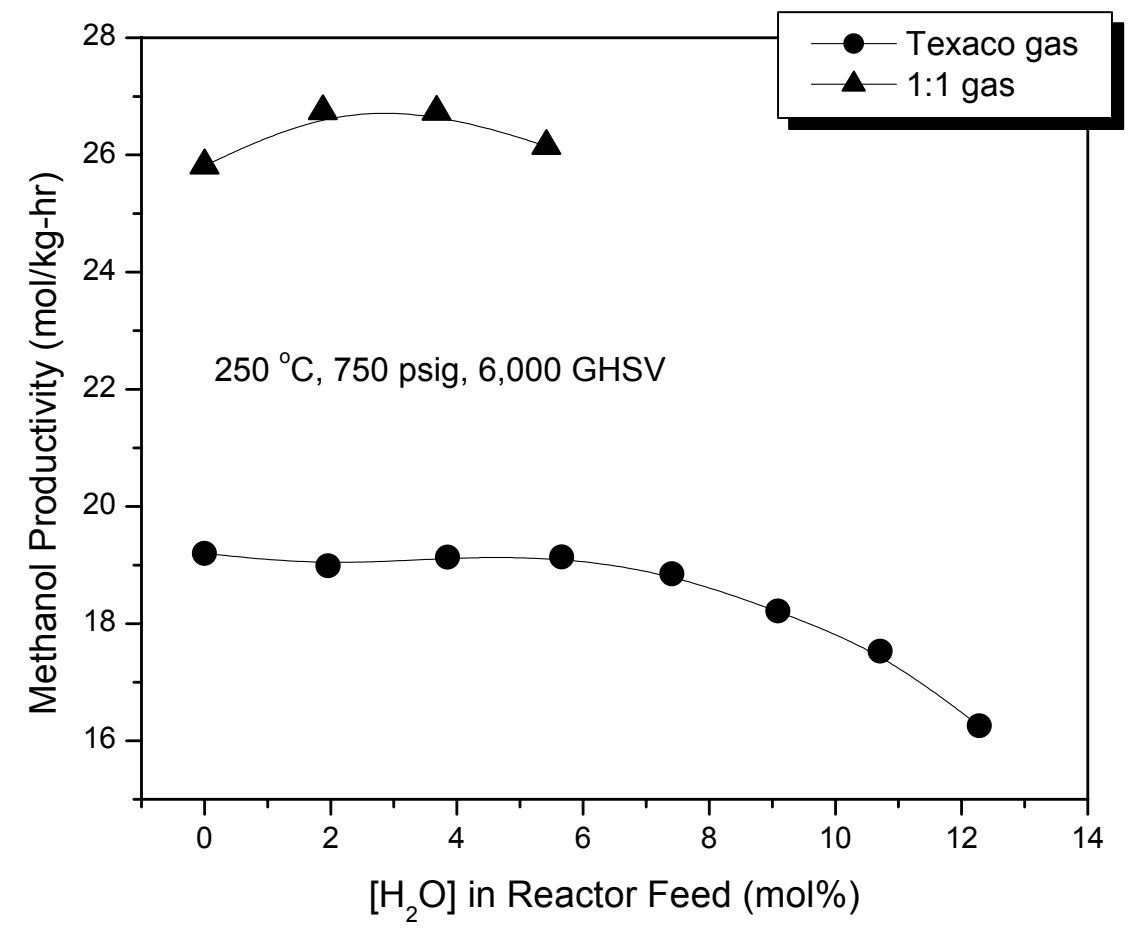

Similar contradicting effects of water injection have been observed previously. An enhancement in productivity is expected since water injection brings the $\mathrm{H}_{2}: \mathrm{CO}$ ratio in the reactor closer to the best ratio for the methanol synthesis kinetics, around 2:1. The question is why this enhancement is not observed in the Texaco case, and stopped before the $\mathrm{H}_{2}$ : $\mathrm{CO}$ ratio reached 2:1 in the Shell and 1:1 cases. Is this due to the hindrance by water or by $\mathrm{CO}_{2}$ ?

Figures $10 \mathrm{a}$ and $10 \mathrm{~b}$ display the concentration of water and $\mathrm{CO}_{2}$ in the reactor effluent from the three water injection experiments. Figure 10a shows that the runs using Shell and 1:1 gas generated similar amounts of $\mathrm{CO}_{2}$. However, one (the Shell gas case) showed significant productivity enhancement, and the other (the 1:1 gas case) showed little enhancement. Figure $10 \mathrm{~b}$ shows that both Texaco and 1:1 cases had much higher water concentration in the reactor than the Shell case; both showed little productivity enhancement. These observations appear to suggest that the variation in the productivity enhancement is directly related to water, but not to $\mathrm{CO}_{2}$. 
Figure 10: Exit $\mathrm{H}_{2} \mathrm{O}$ and $\mathrm{CO}_{2}$ concentrations from water injection experiments

a

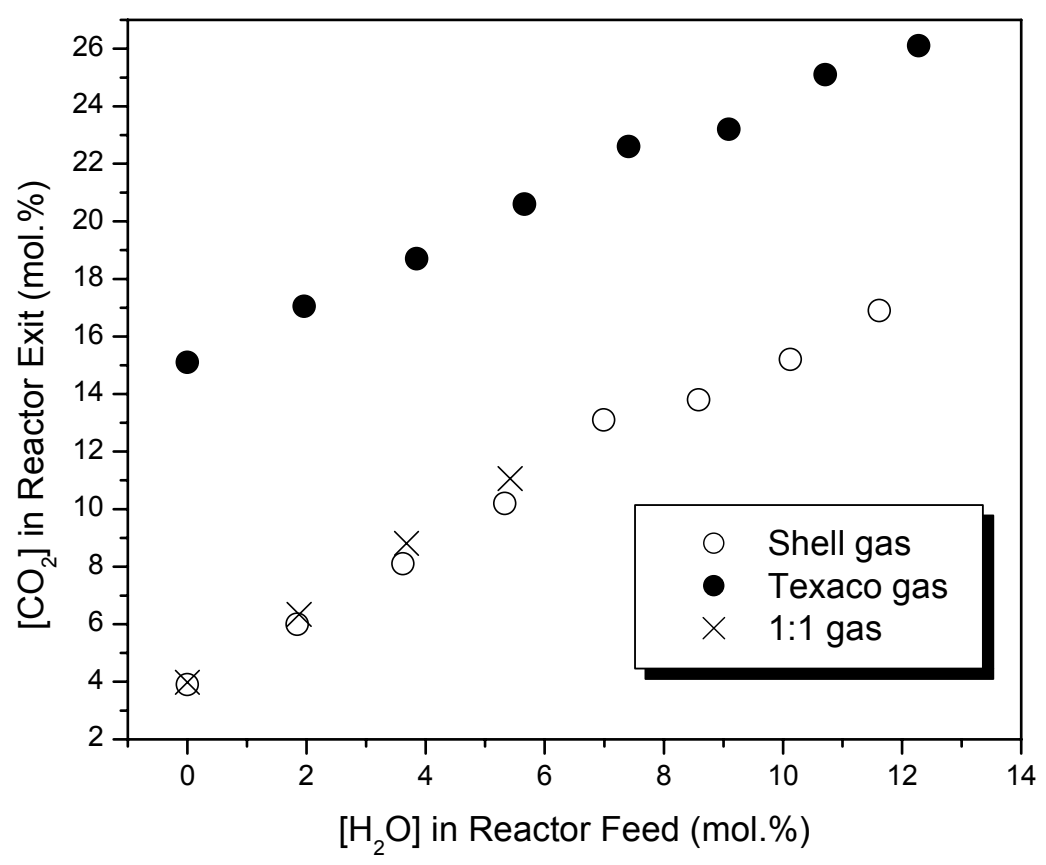

b

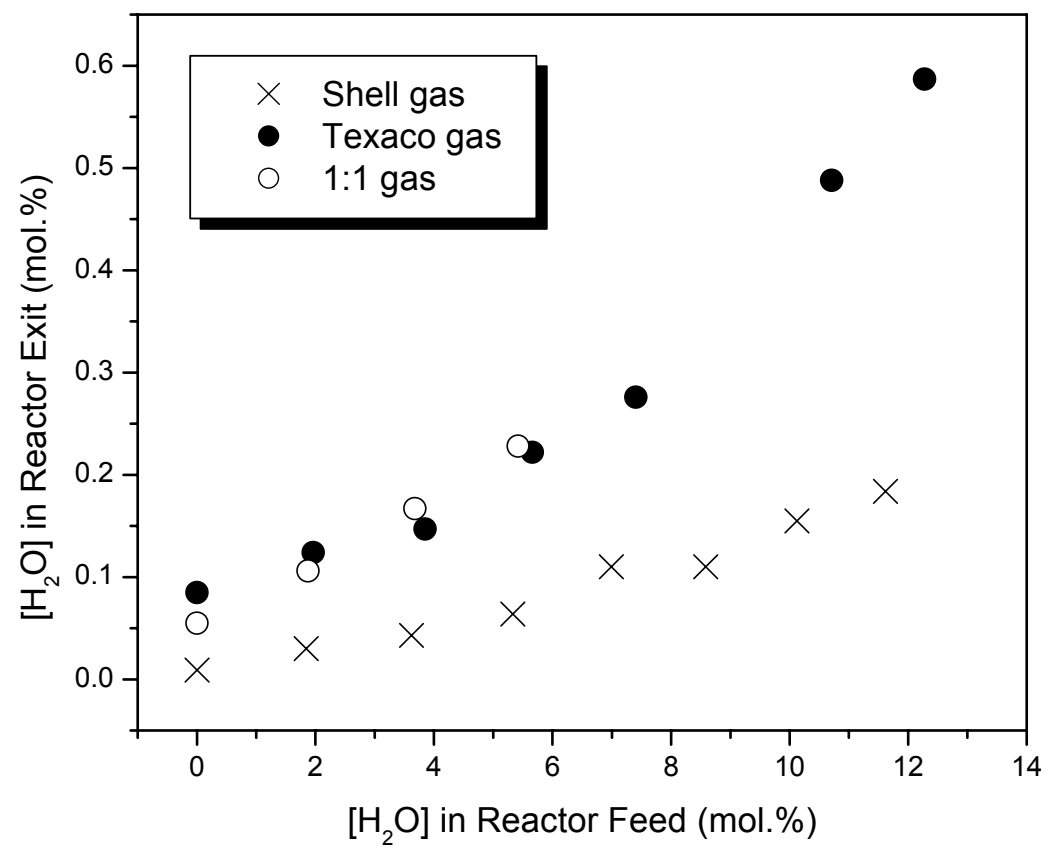




\subsection{Does High Water Concentration Suppress Methanol Synthesis?}

The last water injection experiment was conducted using Kingsport feed gas. This was not for the purpose of productivity enhancement, since the feed was already $\mathrm{H}_{2}$-rich and water injection would only hurt the productivity. The goal was to verify an observation we have had previously: water injection under $\mathrm{H}_{2}$-rich conditions suppresses methanol catalyst activity. In this previous experiment using a feed denoted as "Eastman" gas $\left(50 \% \mathrm{H}_{2}, 38 \% \mathrm{CO}, 9 \% \mathrm{CO}_{2}\right.$ and $\left.2 \% \mathrm{~N}_{2}\right)$ along with water injection, we observed 1) a large drop in the methanol rate constant that is beyond the scatter of the kinetic model and 2) a long transition period ( $>24$ hours) to reach this low, suppressed activity. This occurred when the water injection rate was above a certain level. One set of results under this suppressed condition is shown in Table 10, along with those obtained when only pure Eastman feed was used.

Table 10: Suppression of methanol catalyst activity under certain conditions

\begin{tabular}{l|lllll|l|l|l}
\hline Reactor Feed & \multicolumn{4}{|l|}{ Exit Composition } & (mol \%) & Relative & Slow & Catalyst \\
& $\mathbf{H}_{\mathbf{2}}$ & $\mathbf{C O}$ & $\mathbf{C O}_{\mathbf{2}}$ & $\mathbf{M E O H}$ & $\mathbf{H}_{\mathbf{2}} \mathbf{O}$ & $\mathbf{k}_{\mathbf{m}}$ & Transition? & \\
\hline Eastman/water & 45.3 & 26.7 & 18.0 & 8.8 & 0.59 & 0.68 & Yes & BASF S3-86 \\
\hline Eastman & 38.0 & 35.4 & 12.4 & 12.1 & 0.18 & 1.00 & & BASF S3-86 \\
\hline Kingsport/Water & 60.5 & 11.2 & 7.7 & 13.1 & 0.86 & 1.02 & No & $\begin{array}{l}\text { Current standard } \\
\text { catalyst }\end{array}$ \\
\hline Kingsport & 59.4 & 13.15 & 5.5 & 14.4 & 0.52 & 1.00 & & $\begin{array}{l}\text { Current standard } \\
\text { catalyst }\end{array}$ \\
\hline
\end{tabular}

No such suppression was observed when we conducted water injection using the Kingsport feed $\left(68.1 \% \mathrm{H}_{2}, 21.3 \% \mathrm{CO}, 4.5 \% \mathrm{CO}_{2}\right.$ and $\left.5.2 \% \mathrm{~N}_{2}\right)$. Neither a drastic change in the methanol rate constant nor a slow transition behavior was observed. This was true even when the water concentration in the reactor effluent reached $1.9 \mathrm{~mol} \%$. These results contradict those observed previously using the "Eastman" gas. The possible explanations include that the suppression may be sensitive to certain combinations of gas phase composition, not just $\mathrm{H}_{2}$ or water. Therefore, the two different syngas feeds, Kingsport gas vs. Eastman gas, used in these two experiments could have contributed to the different outcomes, or the suppression is specifically related to the BASF S3-86 methanol catalyst.

\subsection{Catalyst Stability under Water Injection Conditions}

The methanol catalyst stability under LPMEOH ${ }^{\mathrm{TM}}$-with-water-injection conditions was tested. The water injection conditions that led to the best enhancement in the productivity $(32 \%)$ were used. These included Shell gas, $3000 \mathrm{GHSV}$ of syngas, and $9 \% \mathrm{H}_{2} \mathrm{O}$ in the feed (see Figure 8). The run was conducted with alternation between the baseline conditions and the water injection conditions. The baseline conditions provided the data for aging rate calculations to avoid the artifact from our kinetic model. The concentration of water in the reactor effluent during water injection was $0.1 \mathrm{~mol} \%$.

As shown in Figure 11, rapid deactivation $(0.33 \% / \mathrm{hr})$ was observed in the first period of water injection between 100 and 150 hours on stream. The cause is not clear. No such deactivation was observed in our kinetic experiments using Shell gas and water injection. While this is puzzling, and possibly due to an experimental artifact, the catalyst showed very good stability $(0.04 \% / \mathrm{hr})$ in the following two periods of water injection, 170 to 325 and 340 to 390 hours on 
stream. From this experiment, we conclude that the methanol catalyst can be stable under water injection conditions of interest.

Figure 11: Catalyst activity as a function of time on stream under water injection conditions

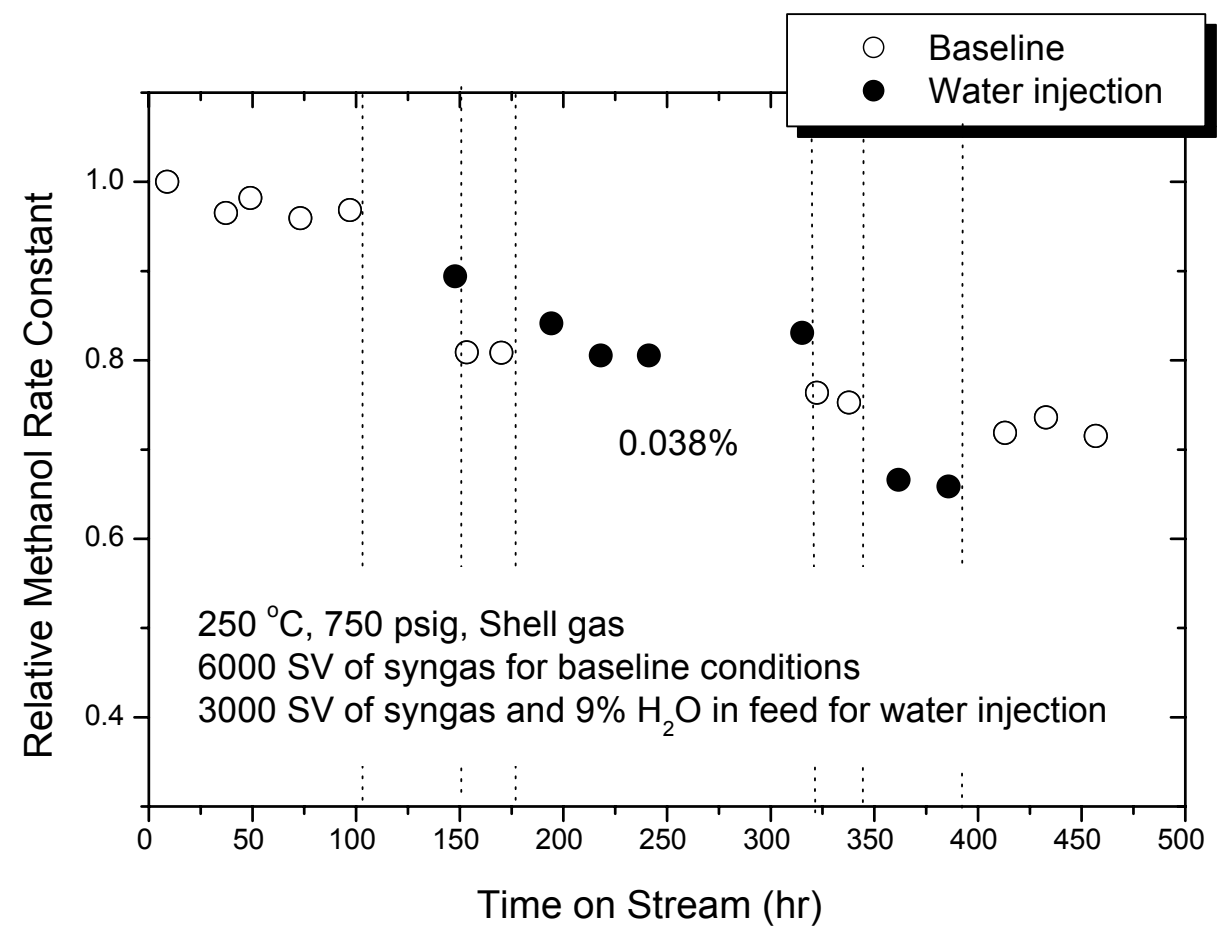

\section{SUMMARY}

Efforts were made to improve our existing kinetic models for the $\mathrm{LPMEOH}^{\mathrm{TM}}$ reaction system. This improvement is needed to meet the requirements for more accurate process simulations over a wide range of reaction conditions. Kinetic experiments under 53 different conditions were conducted. These experiments were designed based on commercial needs and a D-Optimal design package, and produced a database that covers a wide range of reaction conditions. The reaction network was re-analyzed. It was found that a new reaction, $\mathrm{CO}_{2}$ hydrogenation to methanol, needs to be incorporated into the network to account for $\mathrm{CO}_{2}$ conversion more accurately. Another group of reactions, high alcohol formation, was identified, lumped together, and added to the reaction network. New rate models were developed for all 15 reactions in the system. All models showed much improved fit to the experimental data over the entire range of conditions compared to the existing rate models.

In addition to process simulations, another use of a rate model is in catalyst life studies. It was found that different rate models have different sensitivity with respect to the noise in raw kinetic data and the actual variation in reaction conditions. This sensitivity has significant effects on catalyst life studies. It was shown that the life data, e.g., rate constant as a function of time on stream, derived from more sensitive rate models will be more scattered than those from less sensitive models, simply because the errors in the raw data will propagate to the life data (e.g., rate constant) to a greater extent for more sensitive models than less sensitive ones. Another 
issue with the model sensitivity is its effect on the rate of catalyst aging. It was shown that more sensitive models give greater aging rates. Understanding of these model sensitivity related issues should help in catalyst life studies when these issues arise.

A separate effort was made to understand the effect of water injection to the $\mathrm{LPMEOH}^{\mathrm{TM}}$ reactor on the $\mathrm{LPMEOH}^{\mathrm{TM}}$ process. The application is to convert CO-rich gas directly in the $\mathrm{LPMEOH}^{\mathrm{TM}}$ reactor. Water injection can balance the $\mathrm{H}_{2}: \mathrm{CO}$ ratio, and therefore potentially result in greater syngas conversion and reactor productivity. It was found that water injection could either enhance or decrease reactor productivity, depending on the syngas composition. Enhancement as high as $32 \%$ was observed in one case (CO-rich, $\mathrm{CO}_{2}$-low at low space velocity). However, with a CO-rich gas containing a large amount of $\mathrm{CO}_{2}(13 \%)$, water injection resulted in low productivity. It appears that the enhancement is related to the water concentration in the reactor; the syngas that results in lower water concentration in the reactor tends to have a greater enhancement to productivity. A catalyst life test was conducted under the water injection condition that gave $32 \%$ productivity enhancement. The catalyst was stable, and water injection showed no negative effects on catalyst life for this set of conditions. 


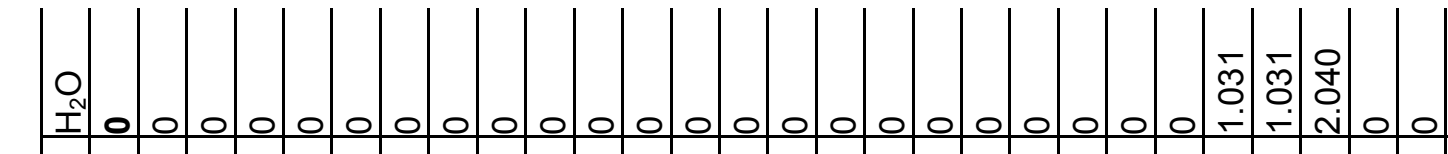

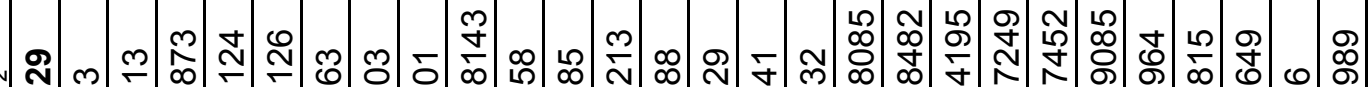
Oల

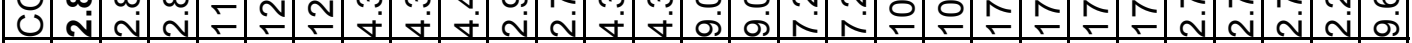

$\frac{2}{\circ}$

1 م

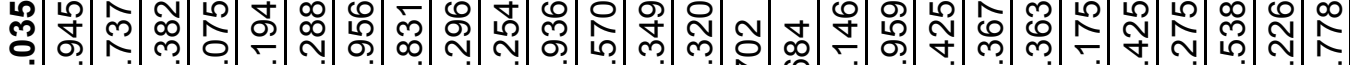

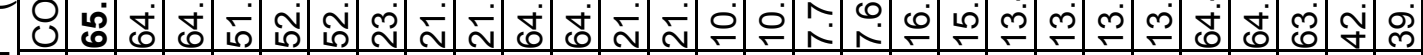
음

竞

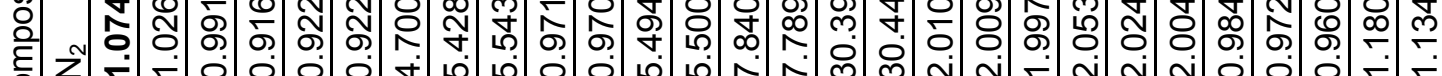

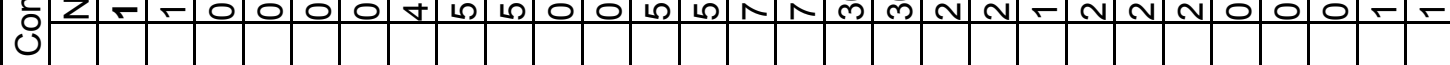

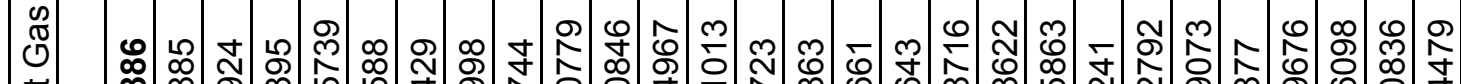

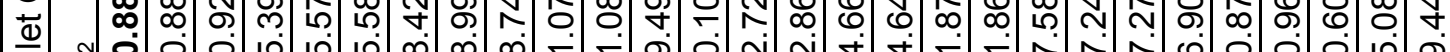
至

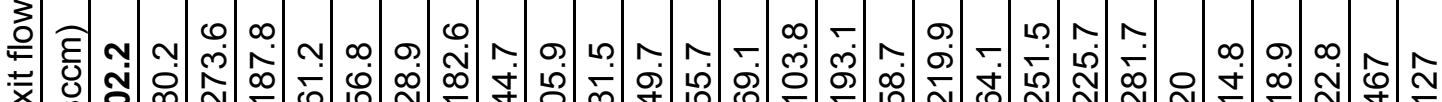

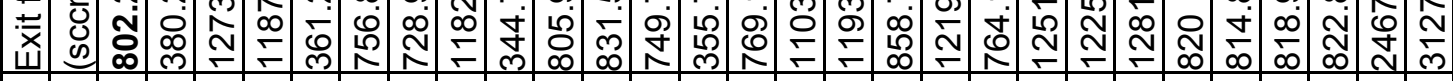
3

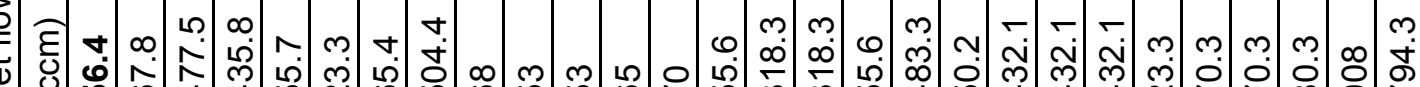

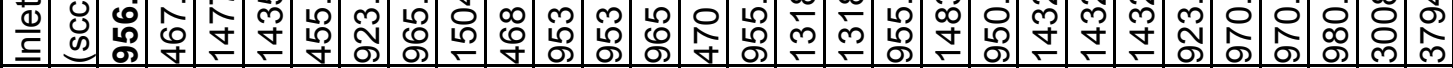

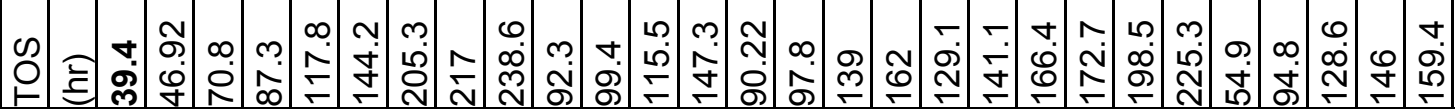

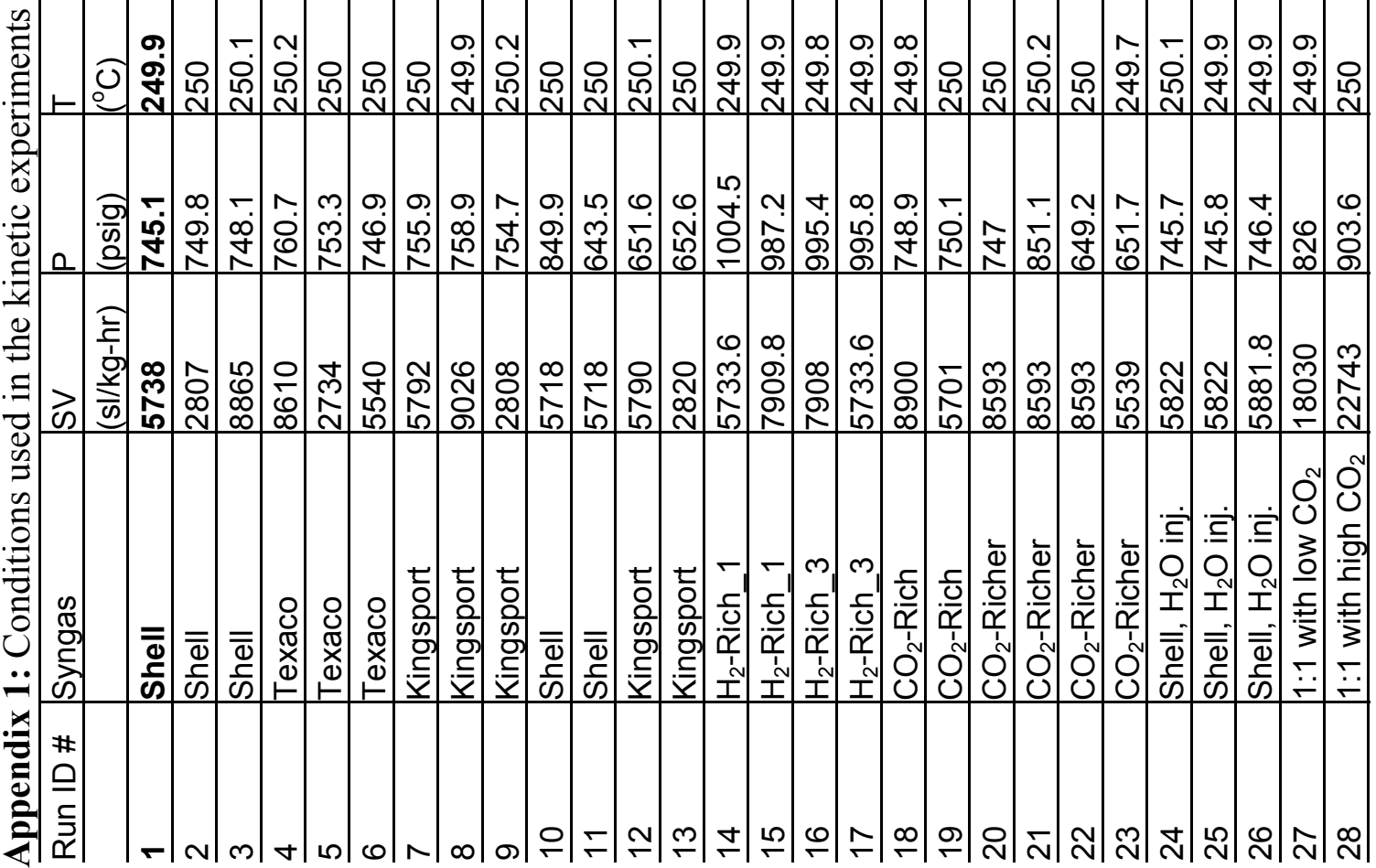




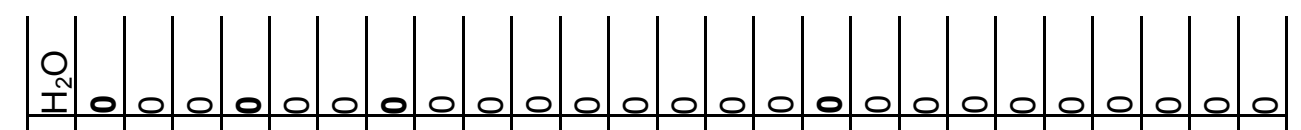

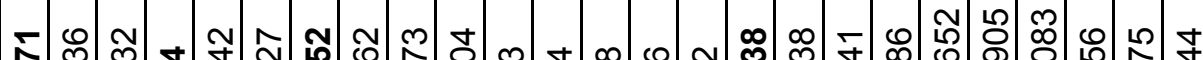
勿

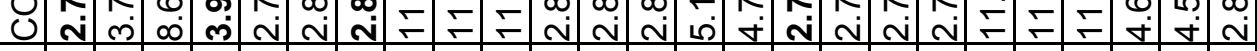

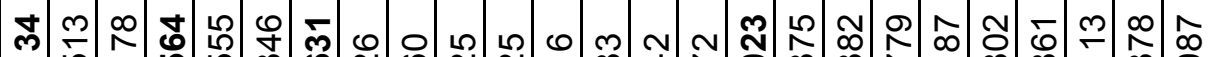
है

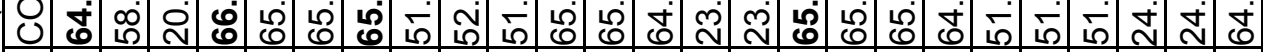
든

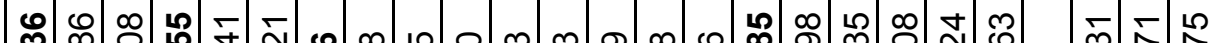
ని

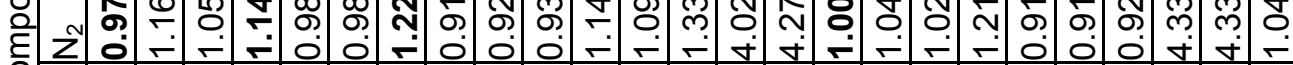

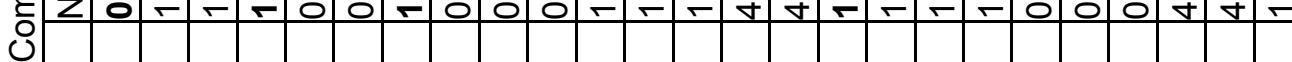

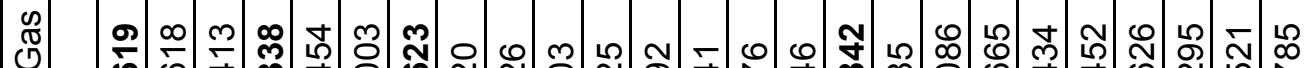
ঢ)

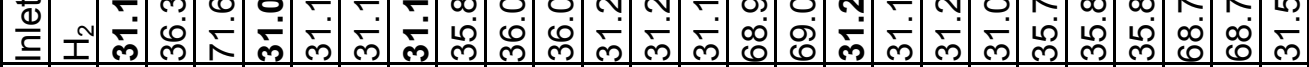
荤

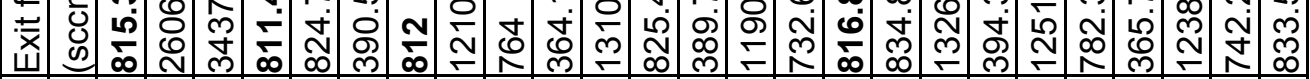

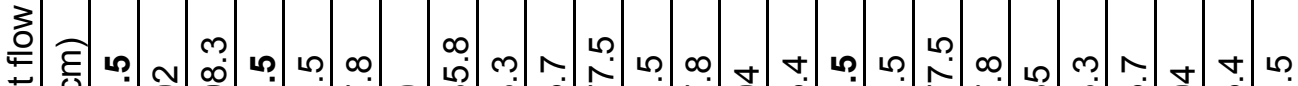
氙

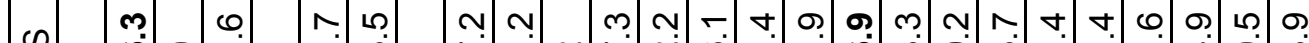
: e

. . 


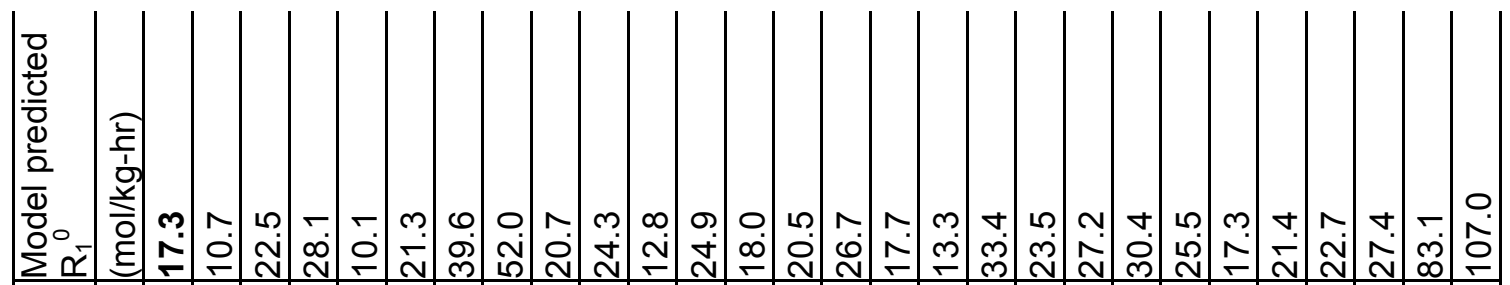

$\bar{\Phi}^{\circ} \bar{x}$

这

ठํํำ

হ⿺辶一兀 نู่

证

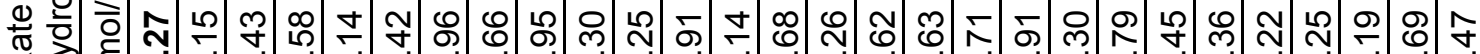

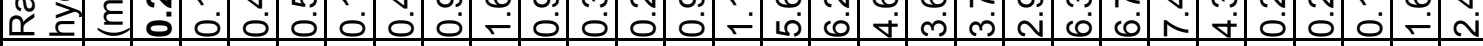

ర్d

¿

范

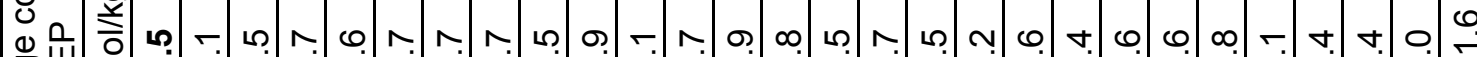

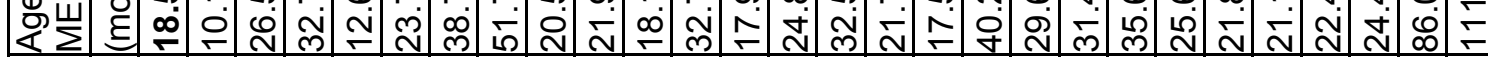

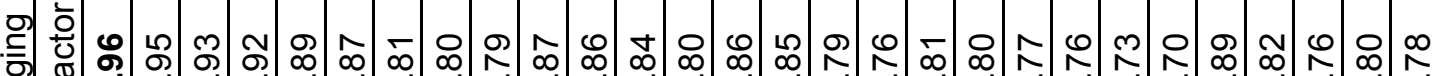

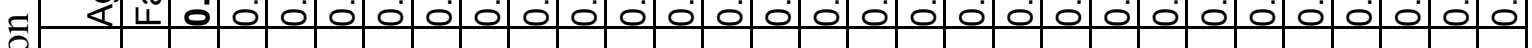

$\widehat{\approx}$

*

穴

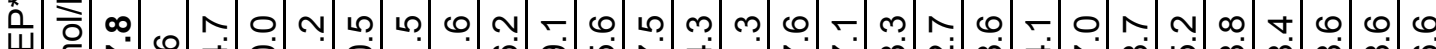

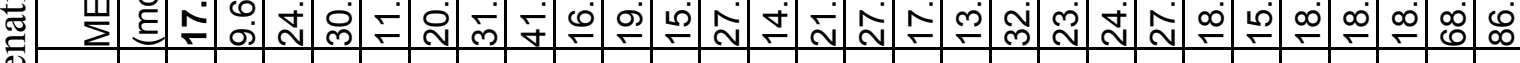

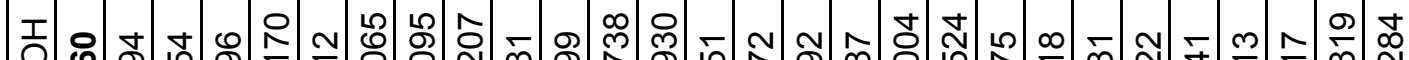
రి

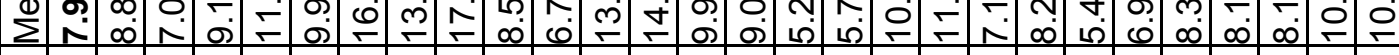

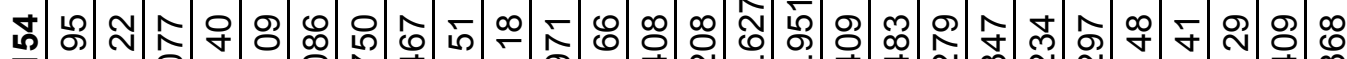
Z

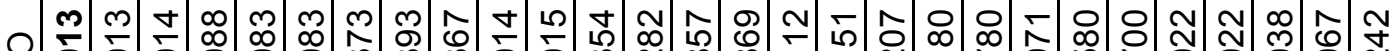
O

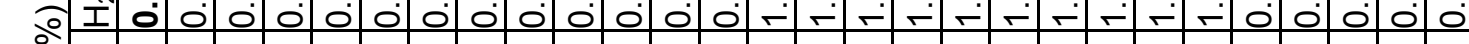
है (

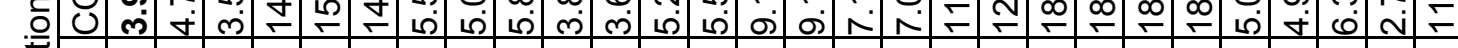

舟의워

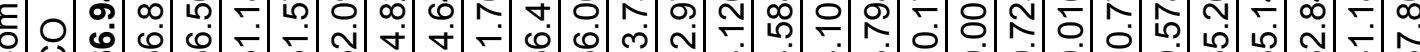

$\ddot{\sim} \quad \stackrel{0}{\mathbb{*}}$

v

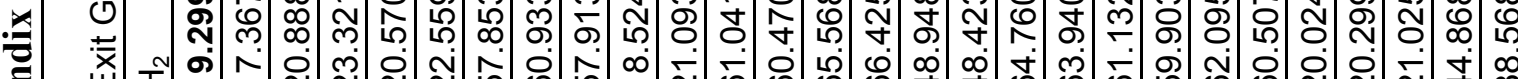

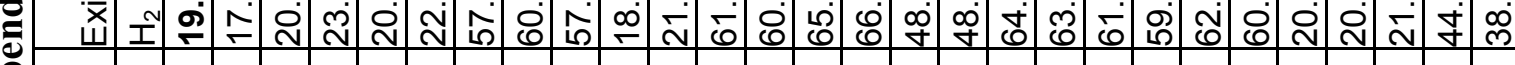

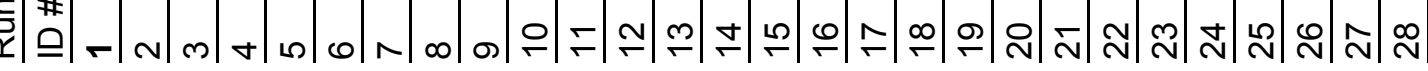




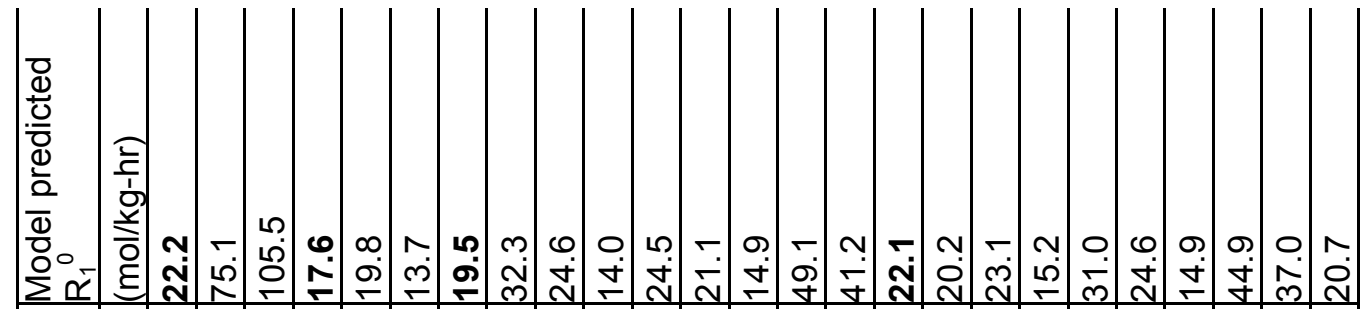

$\bar{\Phi}^{\circ} \bar{x}$

$\div$ :

这 은

0
0
0

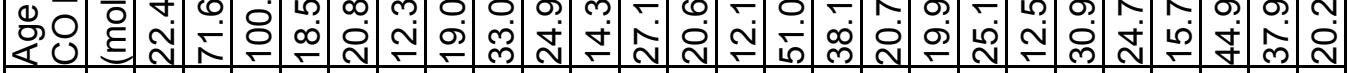

نำ

范

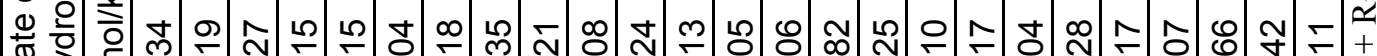

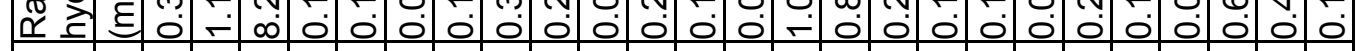

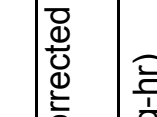

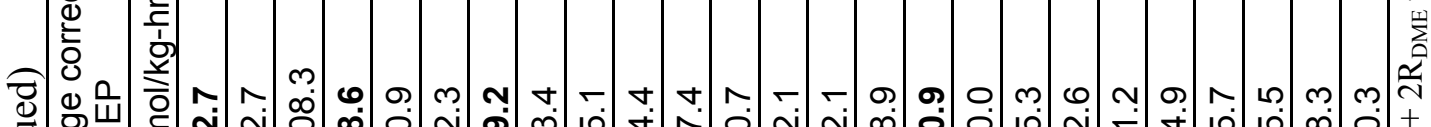

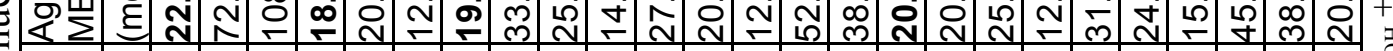

: 히 히

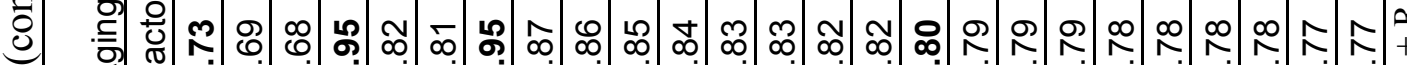

\begin{tabular}{llllllllllllllllllllllllll}
\hline & 0 & 0 & 0 & 0 & 0 & 0 & 0 & 0 & 0 & 0 & 0 & 0 & 0 & 0 & 0 & 0 & 0 & 0 & 0 & 0 & 0 & 0 & 0 & 0 & 0 \\
\hline
\end{tabular}

$\widehat{\hat{\imath}}$

*

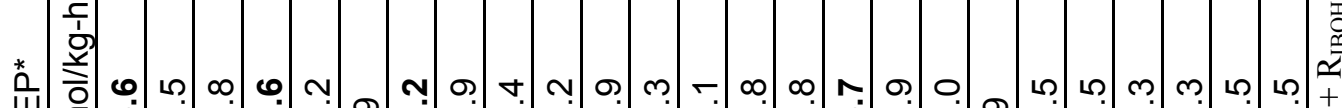

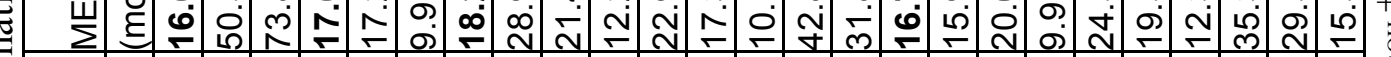

元

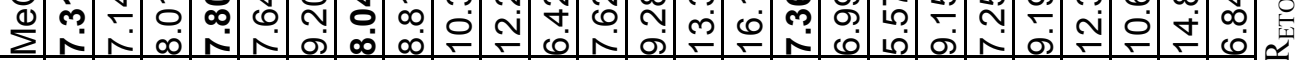

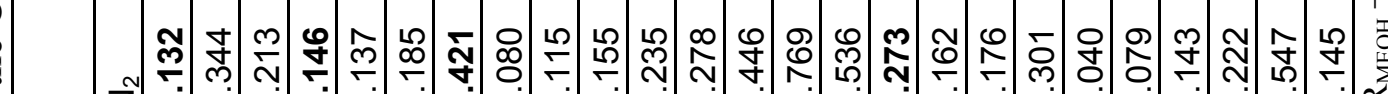

긍

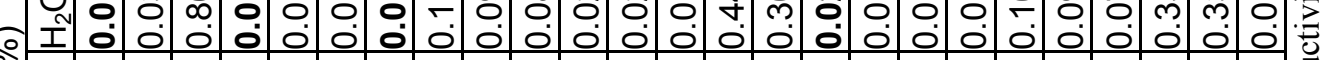

Е

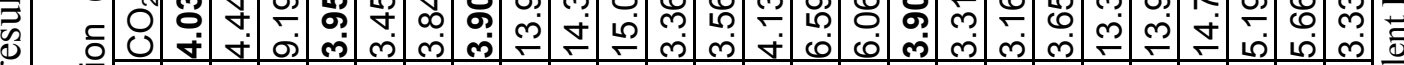

(1)

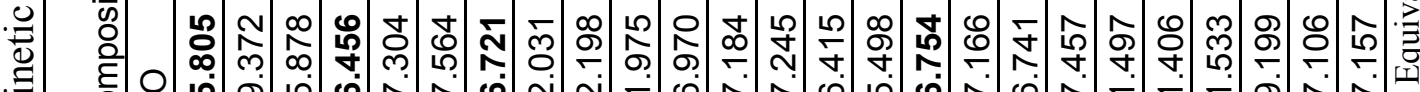
Z 0 ○

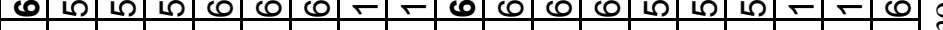

テr

: U I

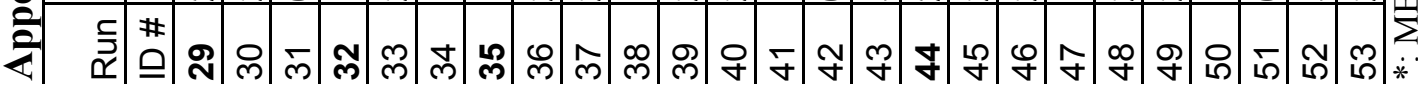




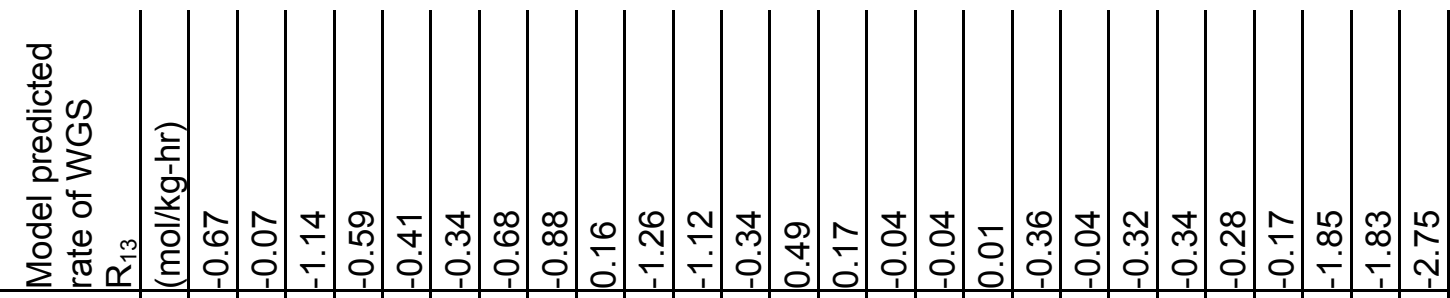

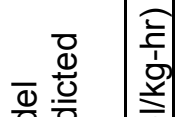

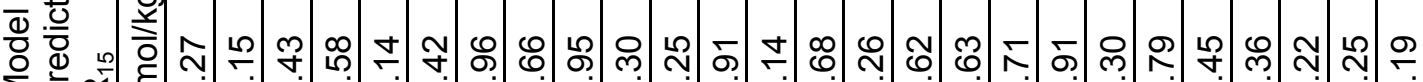

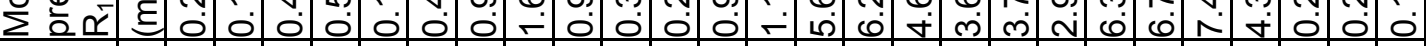

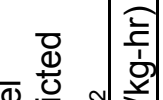

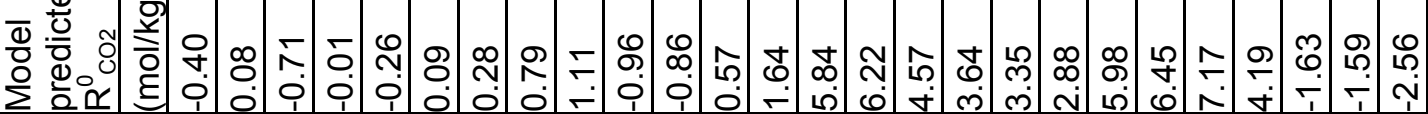

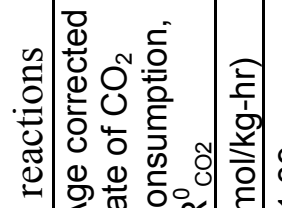

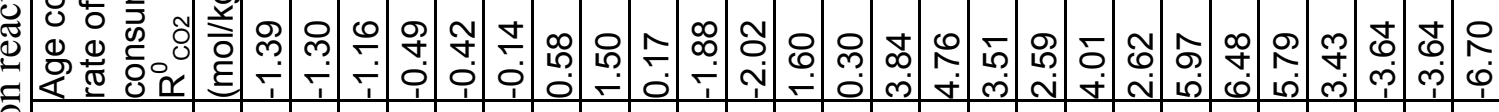
.

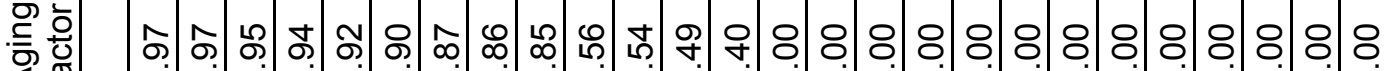

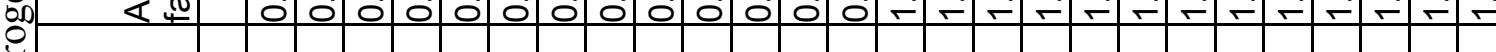

突

-

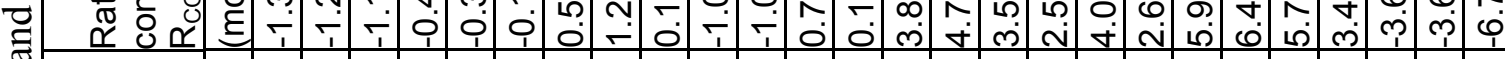

is

D言 3

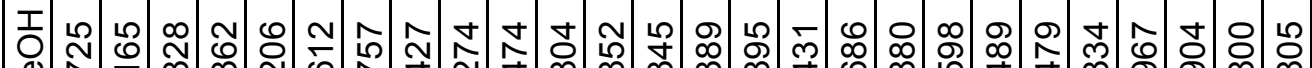

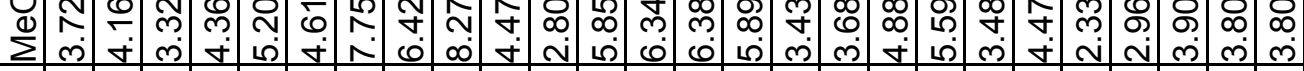

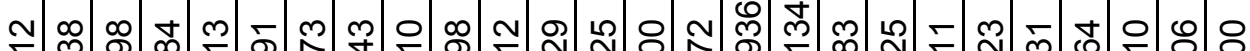

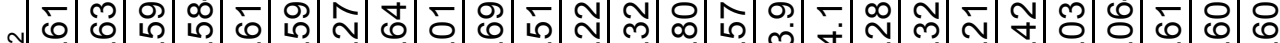

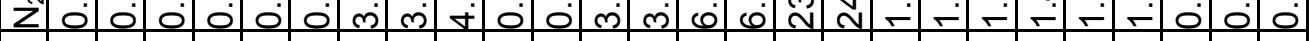
○

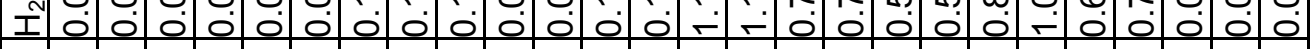

売

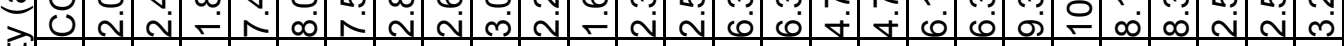

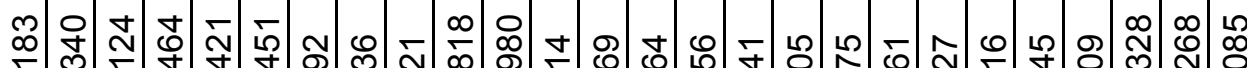

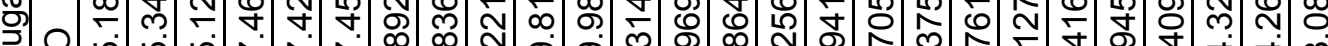

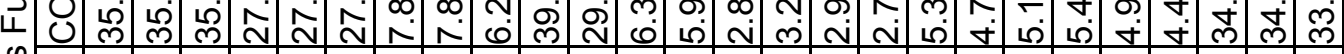

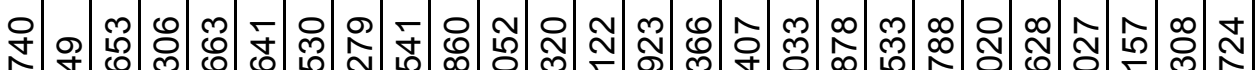

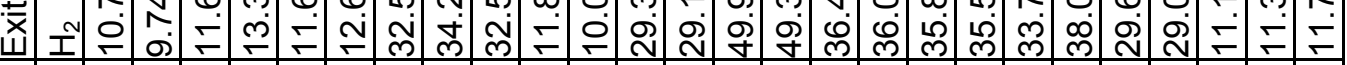

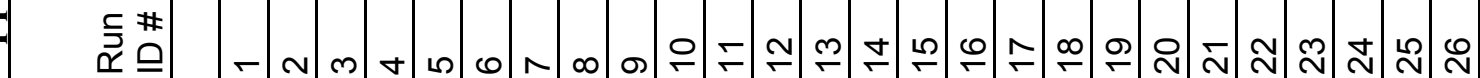

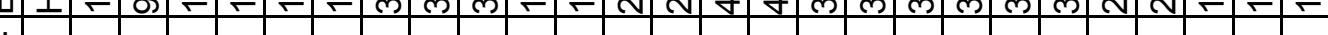


$\frac{0}{10}$

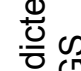

은

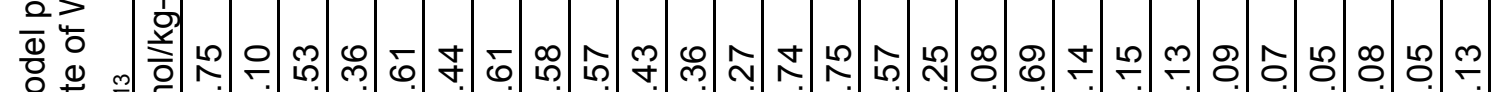

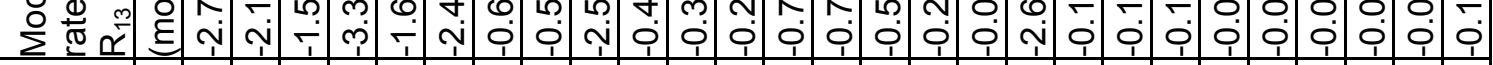

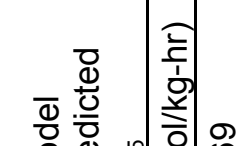

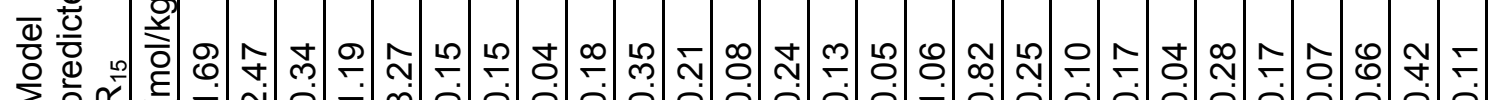

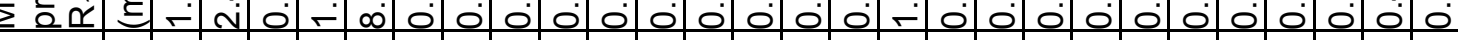

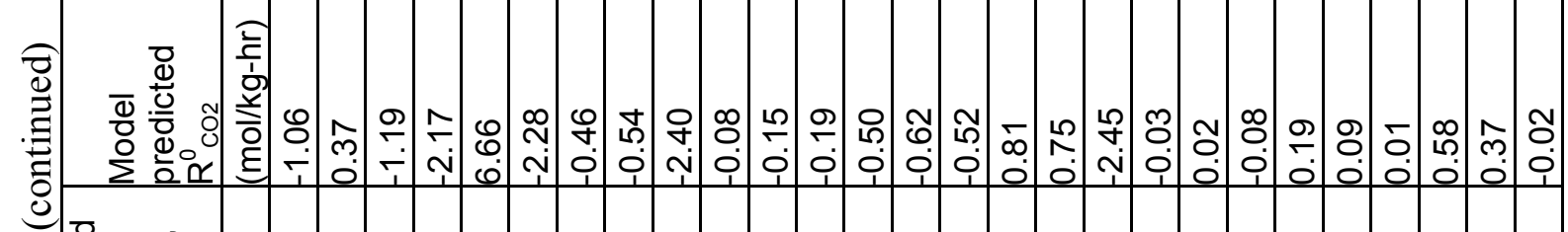
gis

.0ี

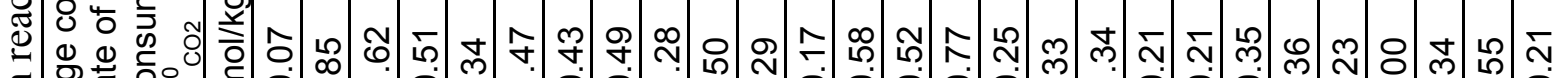

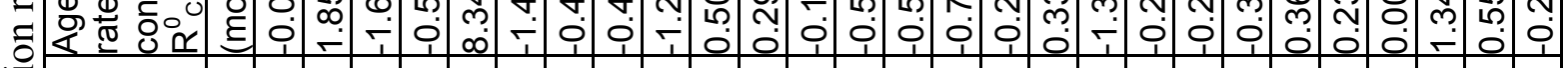

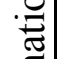

눈 휸

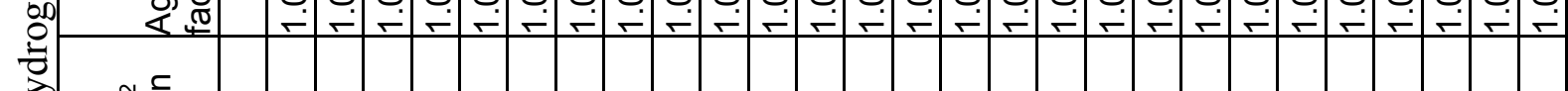

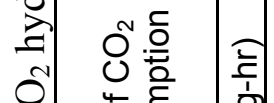

至

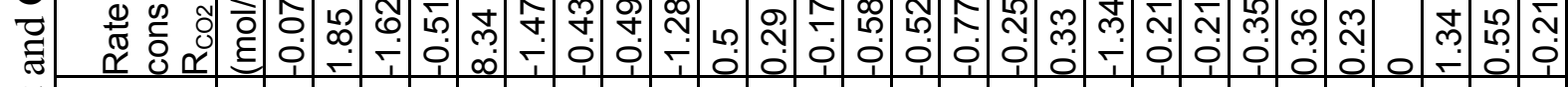

$\stackrel{\leftrightarrows}{\leftrightarrows}$

$\infty \stackrel{1}{1}$

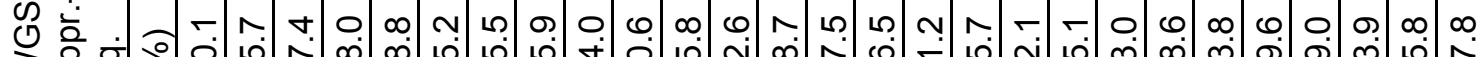

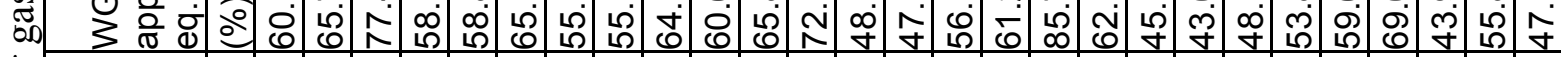

$\frac{\dot{\Phi}}{\stackrel{ \pm}{*}}$

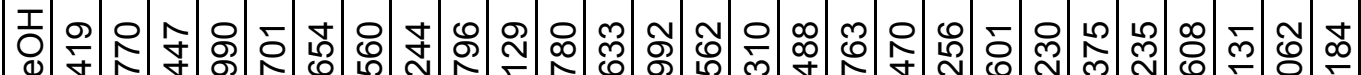

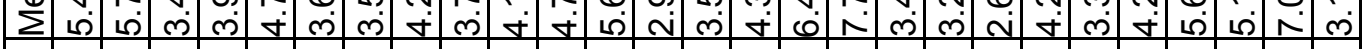
ని న

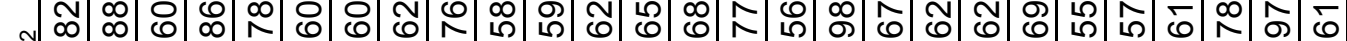

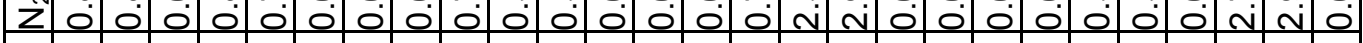
일

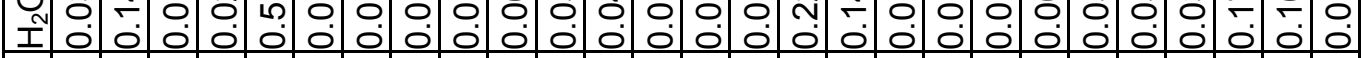

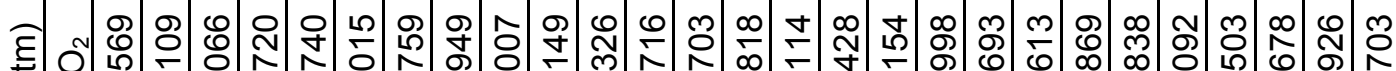

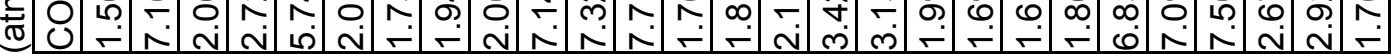

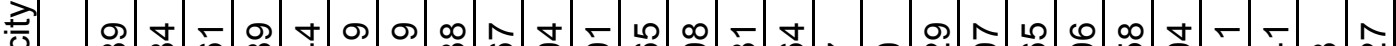

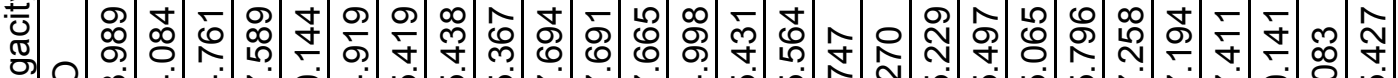

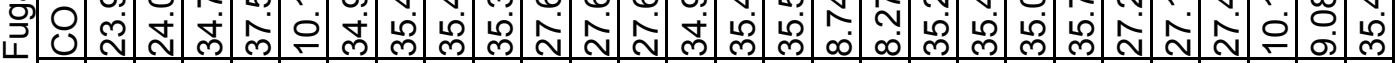

N $\infty$ O G) N

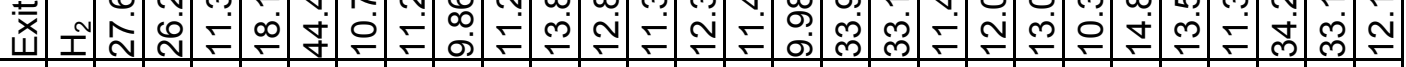

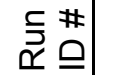

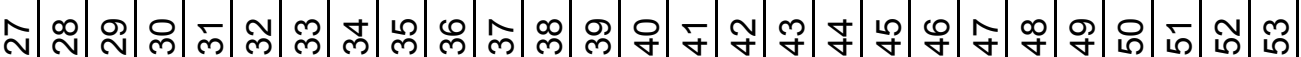




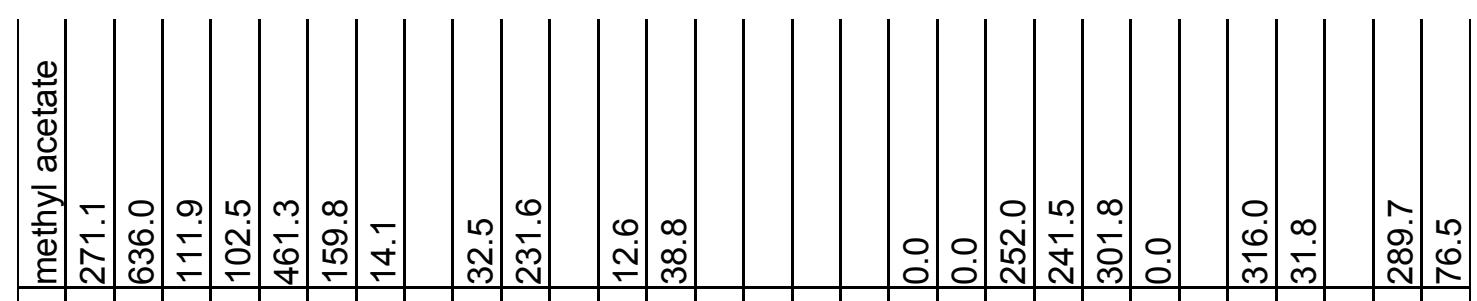



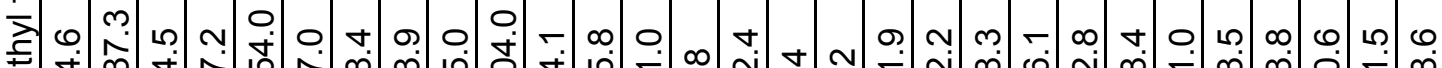

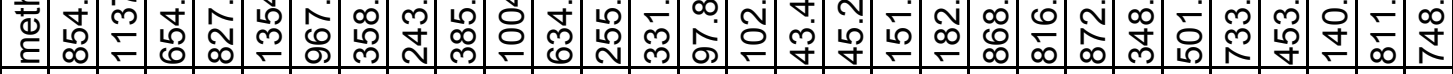

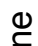

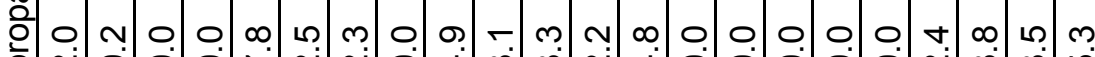

彳

$\stackrel{m}{\forall}$

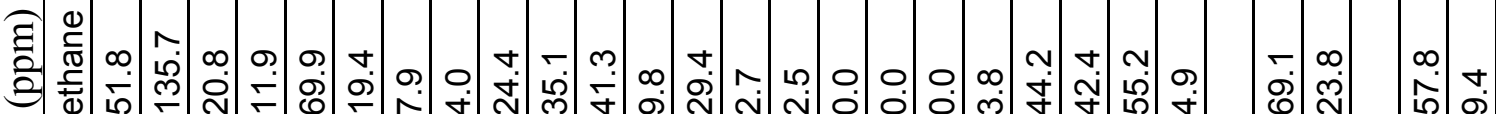

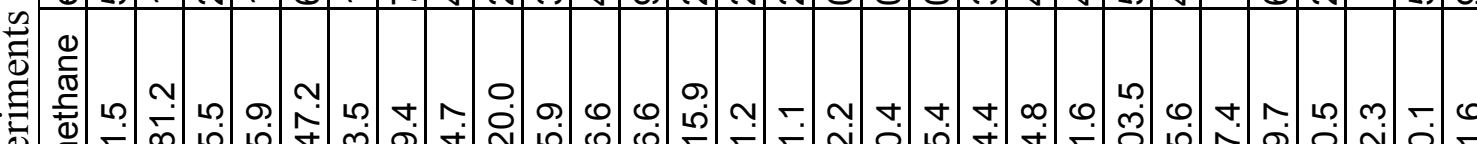

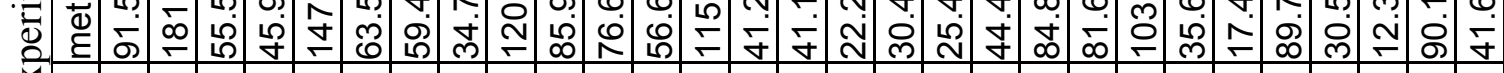

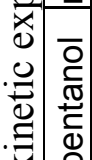

.

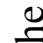

$$
\text { है }
$$

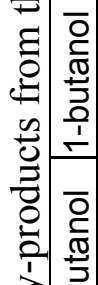

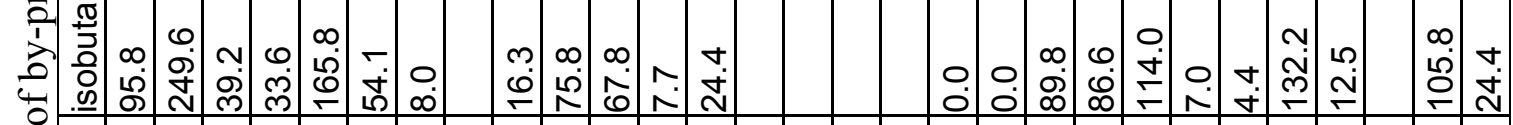

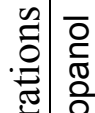

ت⿹

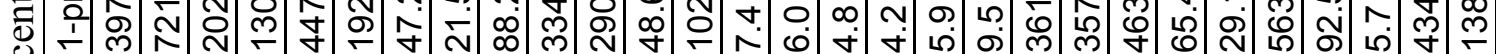

ב-

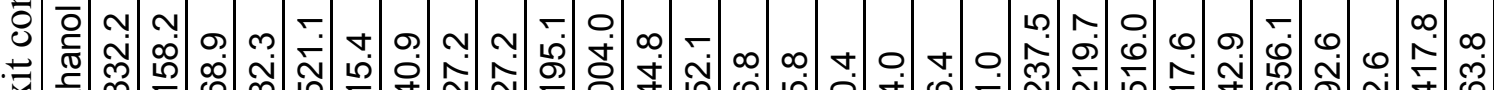

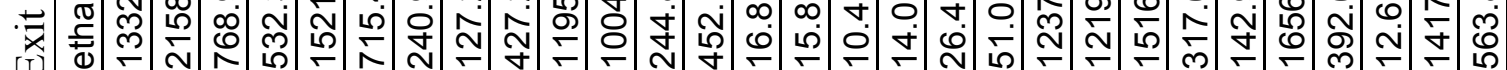

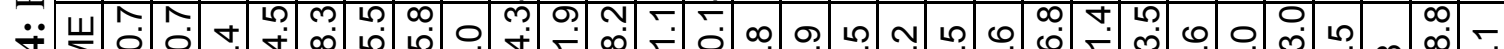
y

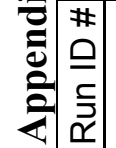




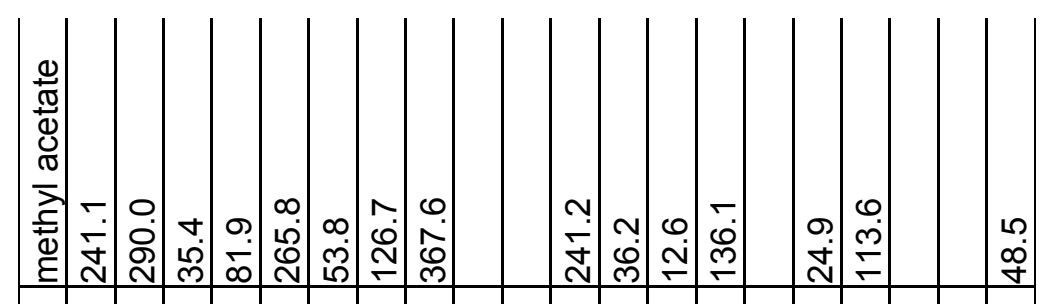
产

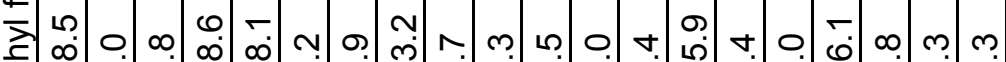

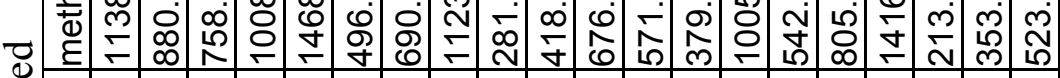

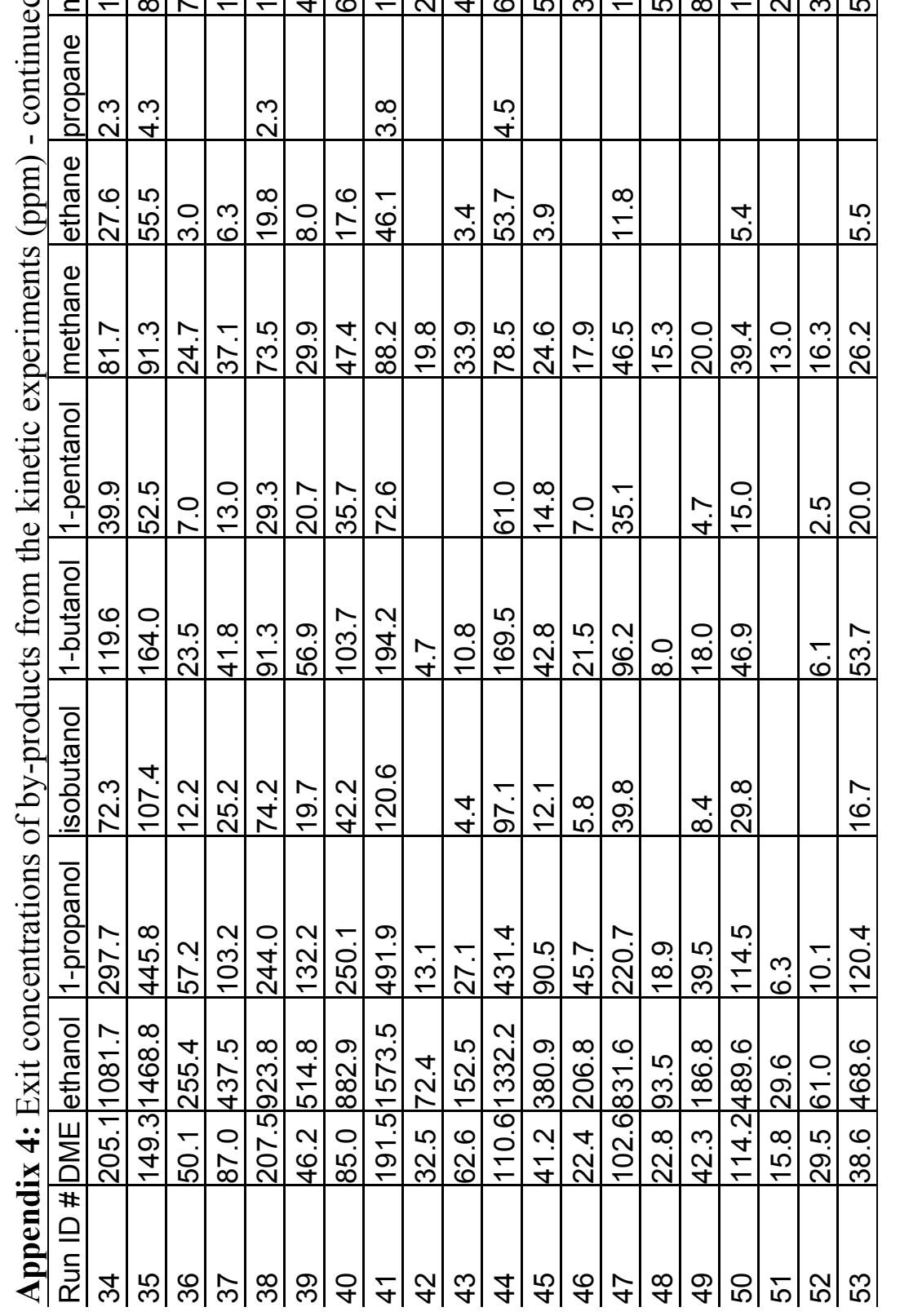




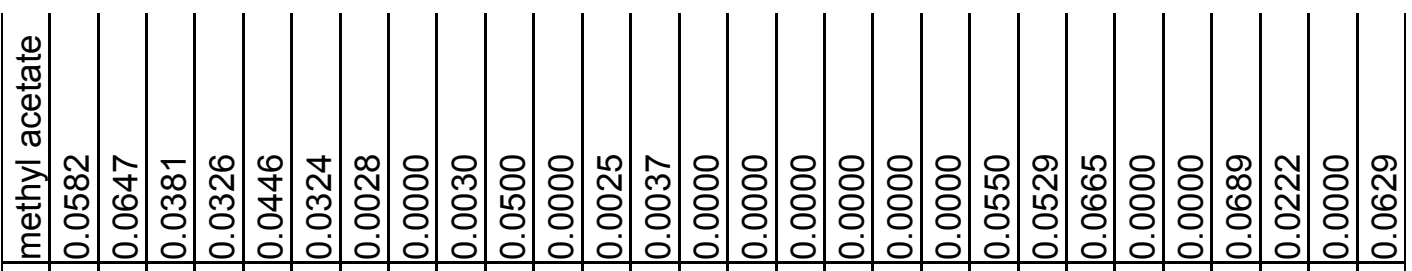

$\stackrel{\oplus}{ \pm}$

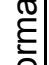

产

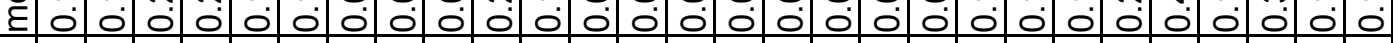

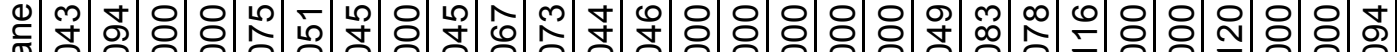

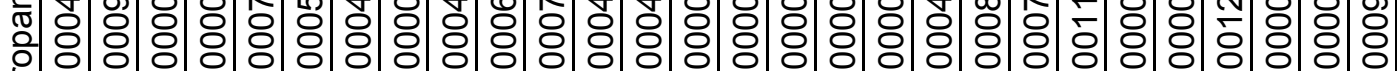

.

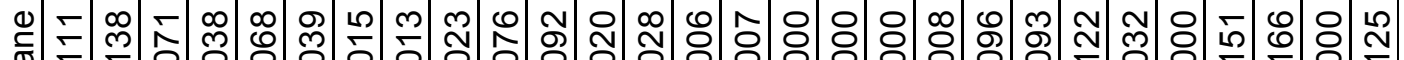

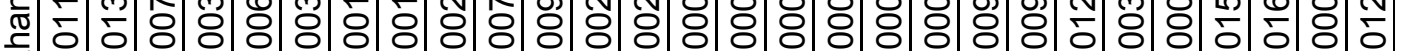
(ิ)

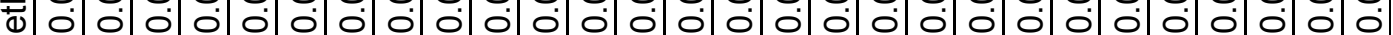

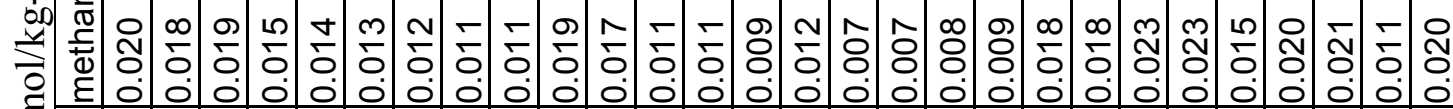
$\exists$

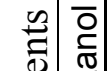

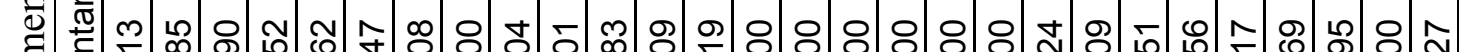
.

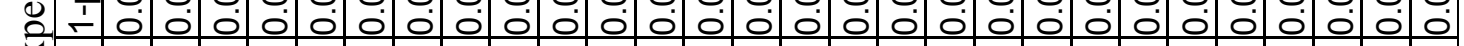
ब)

. .

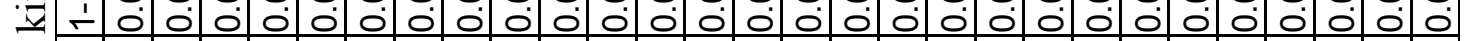
$\stackrel{Ð}{ \pm} \overline{0}$

.

.ฮี

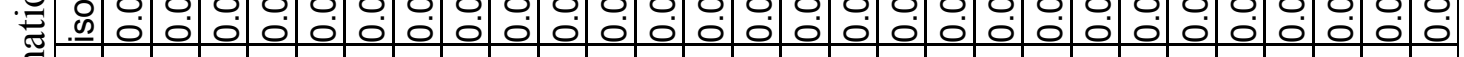

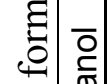

苛 윟ำ

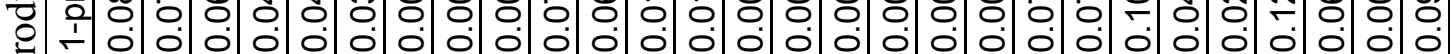
空 วิ등

फ

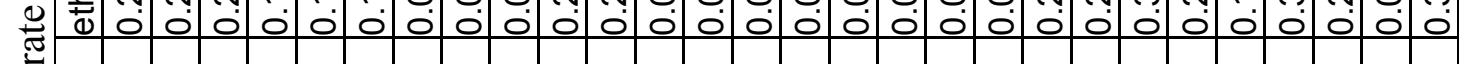

Е

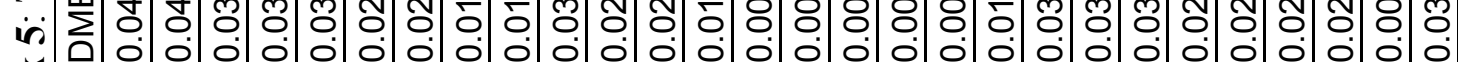

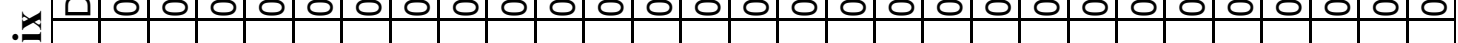
\#

$\frac{2}{2} \frac{2}{5}$

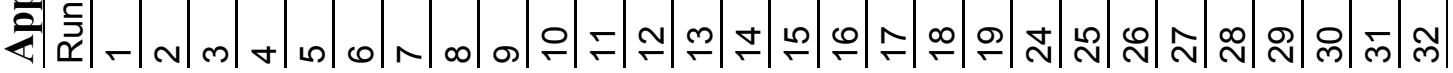




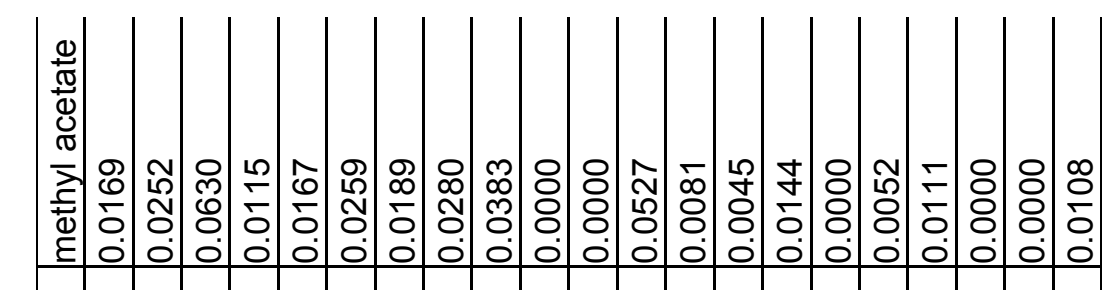
$\stackrel{\oplus}{\pi}$

气ั

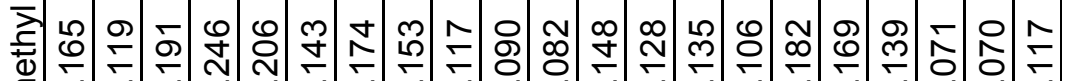

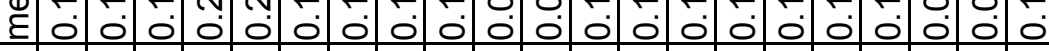

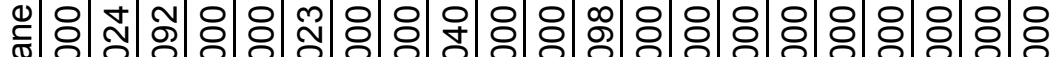

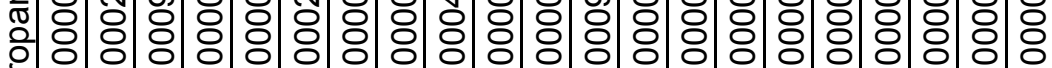

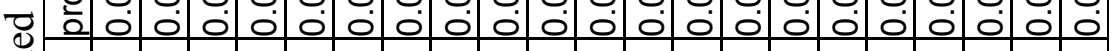

.

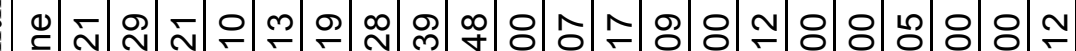

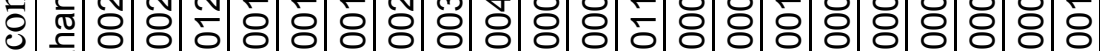

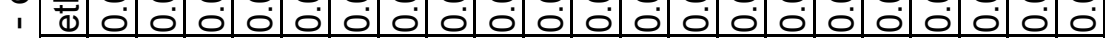
छิ

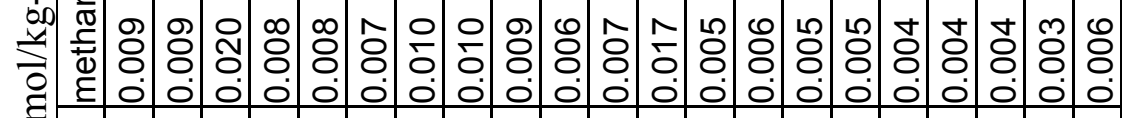
营

व

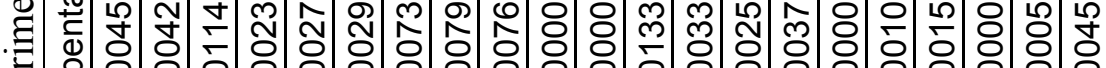
矛 $\begin{aligned} & 1 \\ & 1\end{aligned}$

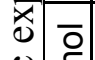

. :

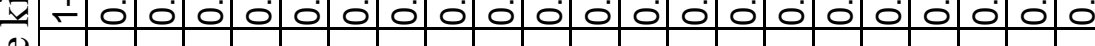

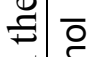

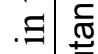

.ี

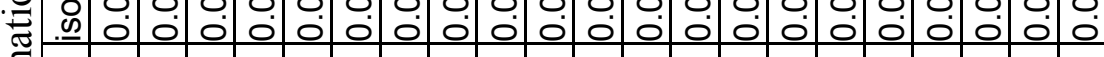

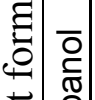

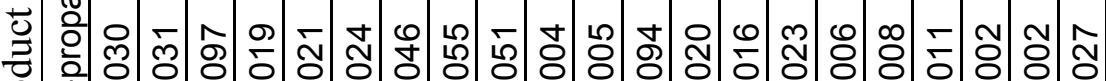

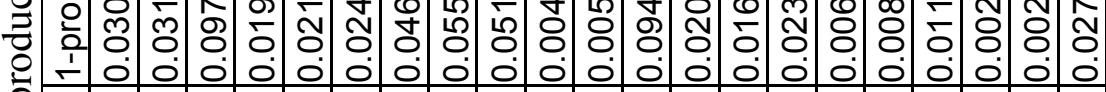
خิ

马े Ч

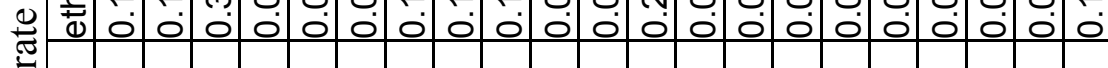

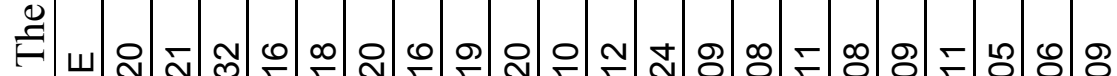

in

n \#

는

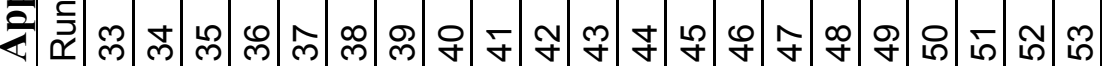




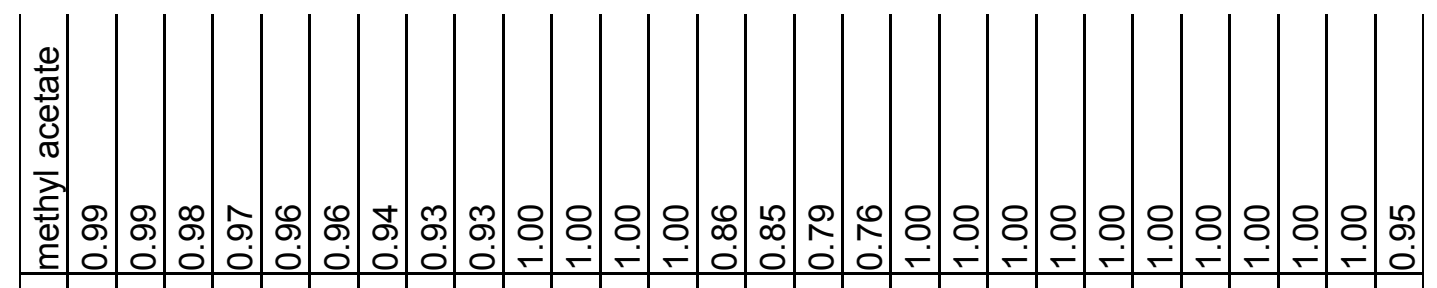

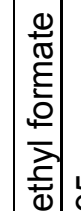

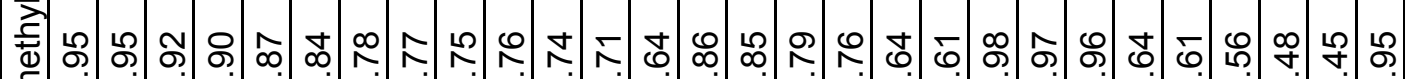

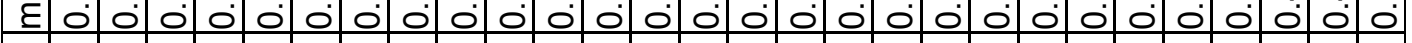
$\stackrel{0}{=}$

잉

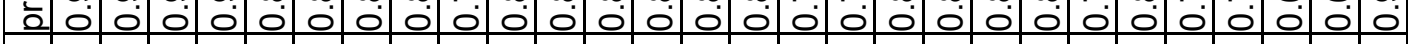

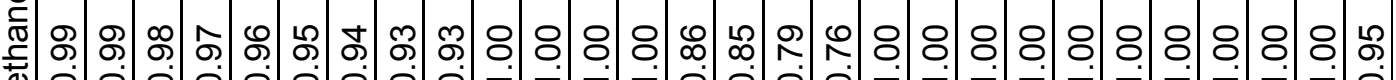

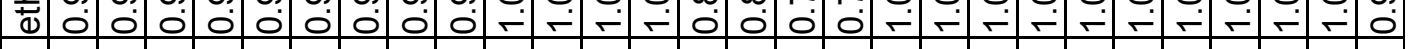

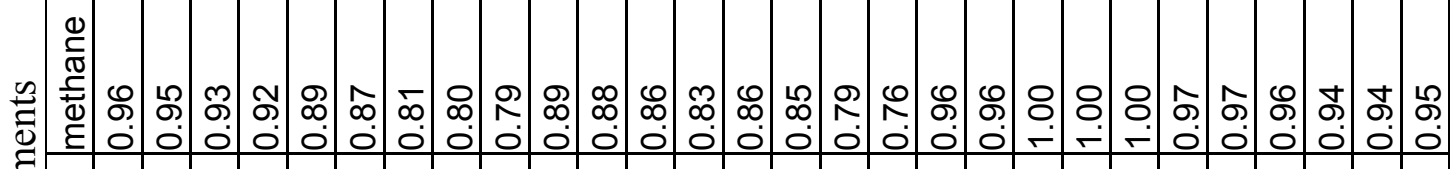

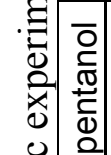

๑ ๑ ๑

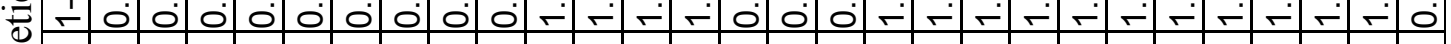
요

‡

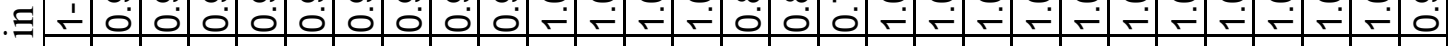

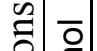

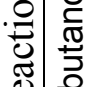

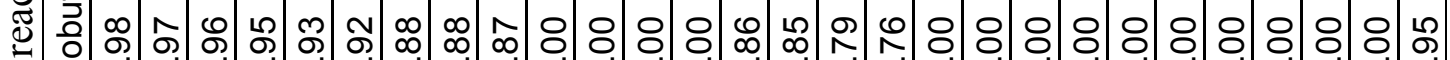

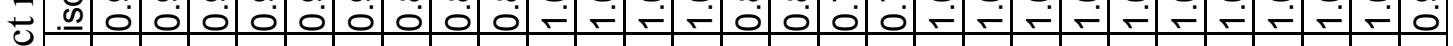
흉 $\overline{0}$

궁

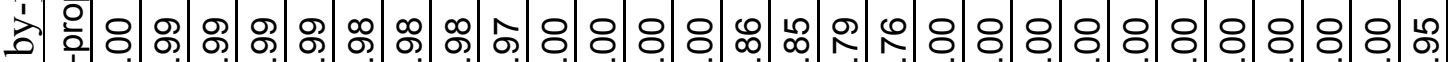

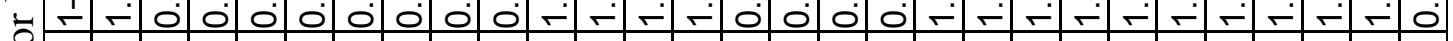
응

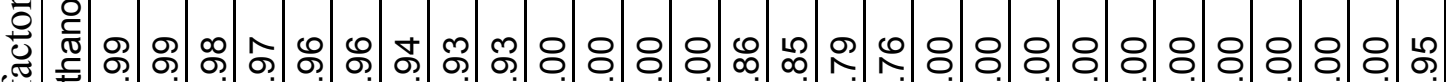

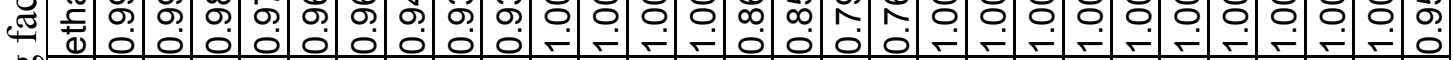
.

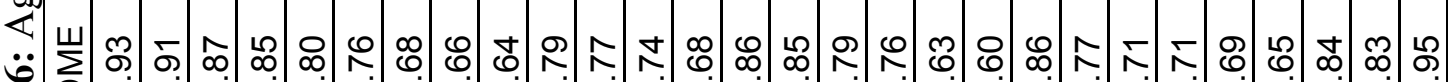

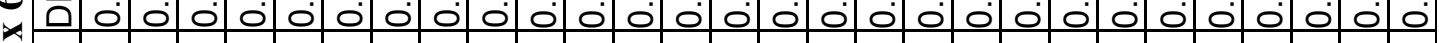

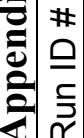




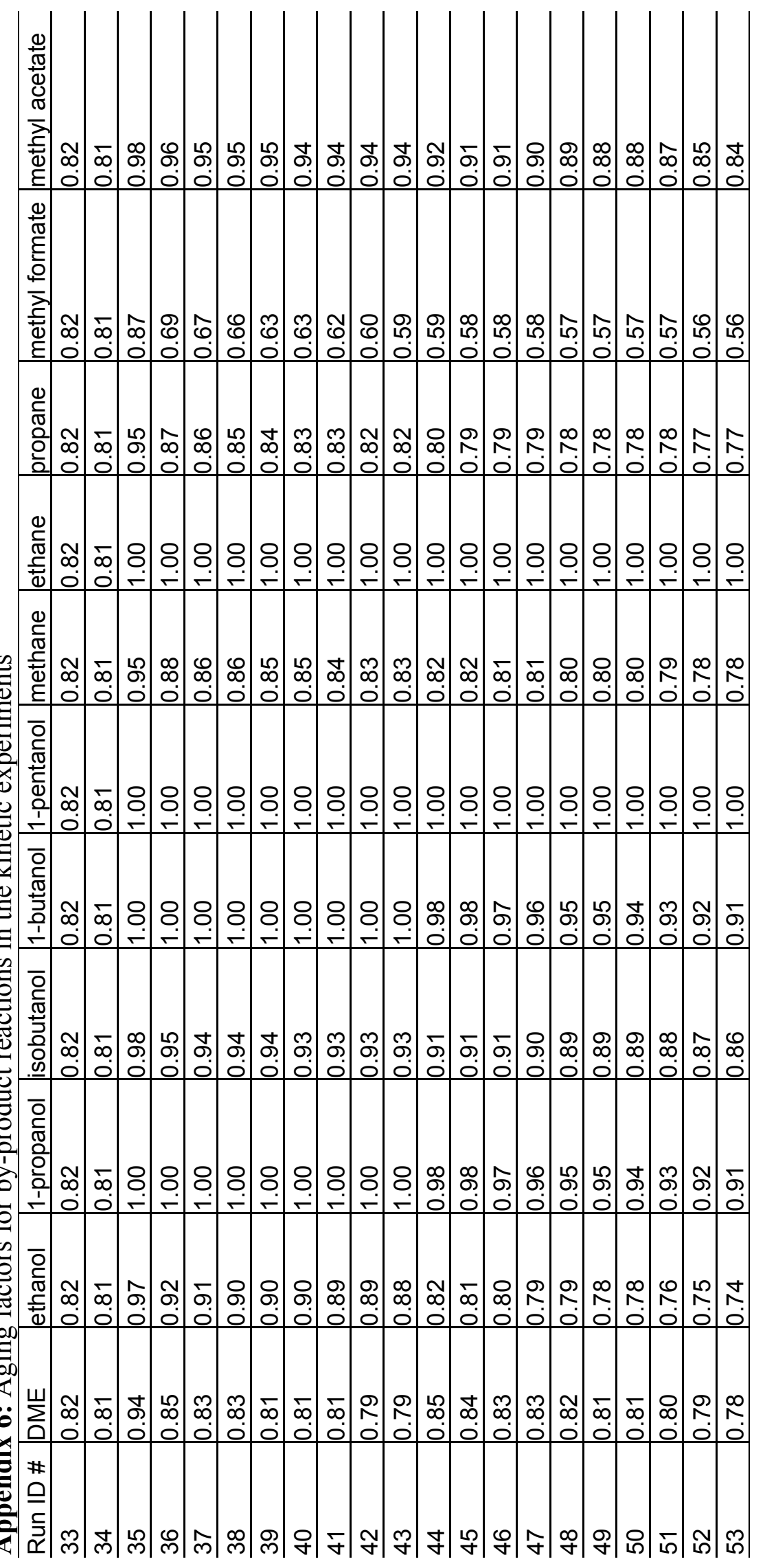

